\title{
Suppression of ovine lymphocyte activation by Teladorsagia circumcincta larval excretory-secretory products
}

\author{
Tom N McNeilly ${ }^{1 *}$, Mara Rocchi', Yvonne Bartley ${ }^{1}$, Jeremy K Brown² ${ }^{2}$ David Frew ${ }^{1}$, Cassandra Longhi ${ }^{1}$, \\ Louise McLean ${ }^{1}$, Jenni McIntyre ${ }^{1}$, Alasdair J Nisbet ${ }^{1}$, Sean Wattegedera', John F Huntley ${ }^{1}$ \\ and Jacqueline B Matthews
}

\begin{abstract}
Teladorsagia circumcincta is an important pathogenic nematode of sheep. It has been demonstrated previously that stimulation of murine T lymphocytes with excretory-secretory (ES) products derived from fourth stage larvae of T. circumcincta (TCi-L4-ES) results in de novo expression of Foxp3, a transcription factor intimately involved in regulatory $T$ cell function. In the current study, Foxp $3^{+} T$ cell responses in the abomasum and the effects of TCi-L4-ES on ovine peripheral blood mononuclear cells (PBMC) following T. circumcincta infection were investigated. $T$. circumcincta infection resulted in a significant increase in numbers of abomasal Foxp3 ${ }^{+} \mathrm{T}$ cells, but not an increase in the proportion of T cells expressing Foxp3. Unlike in mice, Tci-L4-ES was incapable of inducing T cell Foxp3 expression but instead suppressed mitogen-induced and antigen-specific activation and proliferation of ovine PBMC in vitro. This effect was heat labile, suggesting that it is mediated by protein(s). Suppression was associated with up-regulation of interleukin-10 (IL-10) mRNA, and specific monoclonal antibody neutralisation of IL-10 resulted in a 50\% reduction in suppression, indicating involvement of the IL-10 signaling pathway. Suppression was significantly reduced in PBMC isolated from T. circumcincta infected vs. helminth-naïve lambs, and this reduction in suppression was associated with an increase in Tci-L4-ES antigen-specific T cells within the PBMC. In conclusion, we have identified a mechanism by which $T$. circumcincta may modulate the host adaptive immune response, potentially assisting survival of the parasite within the host. However, the impact of TCi-L4-ES-mediated lymphocyte suppression during T. circumcincta infection remains to be determined.
\end{abstract}

\section{Introduction}

Teladorsagia circumcincta is a pathogenic nematode of small ruminants and represents a major constraint on farming. The parasite is endemic in temperate regions worldwide and its associated disease, parasitic gastroenteritis, is common. Infections are associated with production losses in lambs, most notably reductions in appetite and live-weight gains, but the parasite can also cause diarrhea, dehydration and death [1]. T. circumcincta resides in the abomasum, which is analogous to the monogastric stomach, and sheep become infected by ingestion of infective third stage larvae (L3)

\footnotetext{
* Correspondence: Tom.McNeilly@moredun.ac.uk

${ }^{1}$ Moredun Research Institute, Pentlands Science Park, Bush Loan, Penicuik $\mathrm{EH} 26 \mathrm{OPZ}$, UK

Full list of author information is available at the end of the article
}

from pasture. These invade the gastric glands where they develop to fourth stage larvae (L4) and fifth stage larvae (L5) after approximately 10 days. The L5 re-emerge into the lumen to complete development to adult worms around 18 days post-infection (dpi), with egg laying starting at 18-21 dpi. Reductions in appetite and weight gain have been largely attributed to, as yet, undefined components of the anti-parasite immune response rather than as a consequence of damage to host tissue by the parasite per se [2]. That said, severe parasite-induced histopathological changes do occur in the abomasum of infected animals [3]. Globally, control of parasitic gastroenteritis relies heavily on anthelmintics; however, drug resistance in $T$. circumcincta is widespread and everincreasing [4] and alternative methods of control are urgently required. 
Although protective immunity to $T$. circumcincta does occur, it requires continuous infection over a number of weeks to develop [5] and, in practice, is not sufficiently rapid to prevent substantial pasture contamination resulting in major losses in production and clinical disease within the same grazing season. In the absence of further parasite challenge, elements of the protective response which can, for example, result in the induction of inhibited L4, are comparatively short-lived, requiring continuous exposure to $T$. circumcincta to be maintained [6]. This relative delay in acquisition of immunity, as well as the somewhat incomplete nature of the protective response, suggests that, as with other nematode species [7,8], T. circumcincta may actively suppress host immune responses facilitating survival within the host. While the precise effector mechanisms of protective immunity are not fully understood, it is thought to involve both innate and adaptive responses (reviewed in [9]). Local $T$. circumcincta specific IgA appears to play a key role, with significant negative correlations reported between local IgA levels and L3 establishment, L4 development and adult length and fecundity [10,11]. Further evidence of a role for local adaptive responses was obtained in experiments whereby lymphoblasts in gastric efferent lymph derived from immune, previouslyinfected lambs were found to confer protective immunity and memory IgA responses when transferred to helminth-free recipient lambs [12]. Cytokine mRNA profiles in abomasal lymph nodes derived from infected sheep suggest that, in common with other nematode infections [7], the effector response to T. circumcincta is largely Th2- type in nature, in concert with a regulatorytype response [13].

Parasitic nematodes regulate host immune responses through a number of mechanisms including interference with antigen processing, modulation of macrophage and antigen-presenting cell function, interference with cytokine signaling, or induction of immunoregulatory cell types (reviewed in [14]). In many cases, immunosuppressive activity has been attributed to molecules that are excreted or secreted by the nematodes [8]. It was shown recently that excretory-secretory (ES) products from $T$. circumicincta L4 induce de novo expression of Foxp3, a transcription factor intimately involved in regulatory $\mathrm{T}$ cell (Treg) function, in activated murine $\mathrm{CD}^{+}{ }^{+} \mathrm{T}$ lymphocytes in vitro [15], suggesting that the parasite may actively induce regulatory $\mathrm{T}$ cell responses during infection. Studies on Ostertagia ostertagi, a closely related nematode of cattle, demonstrated that its larval stages can suppress lymphocyte activation: peripheral blood lymphocyte proliferative responses to the mitogen, phytohaemagglutinin, were transiently depressed during the prepatent period of infection [16], whilst soluble somatic L4 extracts and L4 ES products from $O$. ostertagi were found capable of suppressing mitogeninduced bovine lymphocyte proliferation in vitro [17]. Whether larval stages of $T$. circumcincta are similarly capable of modulating the ovine immune response is currently unknown. The aim of this study was to determine whether Foxp $3^{+} \mathrm{T}$ cells increase during T. circumcincta infection and, secondly, to explore the capacity of larval ES products to modulate ovine lymphocyte responses.

\section{Materials and methods}

\section{Animals and $T$. circumcincta challenge models}

Animal procedures were performed at Moredun Research Institute (MRI) under license as required by the UK Animals (Scientific Procedures) Act 1986, and ethical approval was obtained from the MRI Animal Experiments Committee. With the exception of ovalbumin-immunized lambs, all animals were raised at MRI under conditions designed to exclude accidental infection with helminthparasites, and were considered helminth-naïve. To provide abomasal mucosal tissue for subsequent immunohistochemical (IHC) analyses, twelve yearling Suffolk-cross lambs were infected with $50000 \mathrm{~T}$. circumcincta L3 and abomasal mucosa collected at post-mortem at five $(n=6)$ and ten $(n=6)$ days post-infection. Abomasal mucosa was collected from a further six, age and breed-matched, helminth-naïve lambs to serve as uninfected controls. For general provision of peripheral blood mononuclear cells (PBMC), blood was collected from six, 6-12 month-old Scottish Blackface cross lambs via jugular venepuncture at a frequency of no greater than two occasions every four weeks. To determine the effects of parasite ES products on antigen-specific lymphocyte responses, PBMC were purified from three, 9 month-old Bluefaced Leicester $\times$ Blackface cross lambs which had been immunized three months previously with $60 \mu \mathrm{g}$ low-endotoxin ovalbumin (EndoGrade ${ }^{\curvearrowleft}$ Ovalbumin, Hyglos $\mathrm{GmbH}$, Bernried am Starnberger See, DE) plus 5 mg Quil A (Brenntag Biosector, Frederikssund, DK) on two separate occasions two weeks apart via the intramuscular route. For isolation of PBMC during the course of a $T$. circumcincta infection, seven, 7 month-old Texel-cross lambs were infected with $2000 \mathrm{~T}$. circumcincta L3 three times a week for four weeks. Faecal samples were collected before challenge and three times a week from day 12 after the first challenge and faecal egg counts (FECs) performed as previously described [18]. Identification to species of parasite eggs within faecal samples was performed using species-specific PCR amplification of the ITS-2 region of ribosomal DNA from hatched first stage larvae [19]. Blood was collected by jugular venepuncture at $0,2,4$ and 6 weeks from the start of infection for subsequent isolation of PBMC. To determine ES antigen-specific lymphocyte proliferation 
following infection, PBMC were collected from five 4month old Texel-cross lambs before and after infection with $2000 T$. circumcincta L3 three times a week for six weeks.

\section{Production of ES products from $T$. circumcincta fourth stage larvae (L4)}

Helminth-free Bluefaced Leicester $\times$ Blackface lambs (< 6 months-old) were infected with $50000 \quad T$. circumcincta L3 and mucosal stage L4 harvested at $7 \mathrm{dpi}$ following previously described methods [20]. The parasites were washed three times in PBS before culturing in RPMI 1640 (Invitrogen, Carlsbad, CA, USA) containing $1 \%(\mathrm{v} / \mathrm{v}) \mathrm{D}$-glucose, $2 \mathrm{mM}$ L-glutamine, $100 \mathrm{U} / \mathrm{mL}$ penicillin, $100 \mu \mathrm{g} / \mathrm{mL}$ streptomycin, $250 \mu \mathrm{g} / \mathrm{mL}$ gentamycin and $125 \mu \mathrm{g} / \mathrm{mL}$ amphotericin $\mathrm{B}$, at $37{ }^{\circ} \mathrm{C}$ in $5 \% \mathrm{CO}_{2}$. Culture supernatants were harvested after $24 \mathrm{~h}$ and the media replenished. Parasites were cultured for a further $24 \mathrm{~h}$, when the supernatants were collected and the parasites discarded. Viability of the parasites was confirmed at the end of the culture period on the basis of structural integrity and motility. The culture supernatants were clarified by centrifugation, then passed through $0.2 \mu \mathrm{m}$ sterile filters. L4 ES products were subsequently concentrated approximately 40-fold using an Amicon Ultra-15 centrifugal filter with a $10 \mathrm{kDa}$ cut-off (Sigma-Aldrich, St. Louis, MO, USA). Protein concentrations were assessed using a Pierce BCA protein assay kit according to the manufacturer's instructions (Thermo Scientific) and aliquots stored at $-80{ }^{\circ} \mathrm{C}$ prior to use. For some experiments, endotoxin was removed from the L4 ES products using an EndoTrap ${ }^{\circledR}$ red column according to the manufacturer's instructions (Hyglos $\mathrm{GmbH}$ ). Endotoxin levels were quantified using a LAL Chromogenic Endpoint Assay kit (Hycult ${ }^{\circ}$ biotech, Uden, The Netherlands) and were $3 \times 10^{5} \mathrm{EU} / \mathrm{mg}$ before endotoxin removal and $<100 \mathrm{EU} / \mathrm{mg}$ after removal.

\section{Immunohistochemistry}

Abomasal mucosal tissue was fixed in 4\% paraformaldehyde in PBS and paraffin-embedded. Tissue sections were cut to $5 \mu \mathrm{m}$ thick and mounted on Superfrost Plus glass slides (Thermo Fisher Scientific, Waltham, MA, USA). Single IHC labeling of Foxp3 and CD3 was performed as follows: sections were rehydrated and antigen-retrieval performed by autoclaving at $121{ }^{\circ} \mathrm{C}$ for $10 \mathrm{~min}$ in $10 \mathrm{mM}$ citrate buffer, $\mathrm{pH}$ 6.0. Slides were incubated in $0.3 \%$ hydrogen peroxide for $20 \mathrm{~min}$ at RT to quench endogenous peroxidase activity followed by blocking in $25 \%$ normal goat serum (NGS) in PBS/0.5\% Tween 80 (PBS/T80) for $1 \mathrm{~h}$ at RT. Sections were then incubated overnight at $4{ }^{\circ} \mathrm{C}$ with $5 \mu \mathrm{g} / \mathrm{mL}$ of mouse anti-human Foxp3 monoclonal antibody (mAb) 22510 (mAbcam 22510, Abcam, Cambridge, UK) which had previously been shown to cross-react with ovine Foxp3 [21], $2 \mu \mathrm{g} / \mathrm{mL}$ polyclonal rabbit anti-human CD3 antibody (Dako UK Ltd., Ely, UK) or the appropriate controls (mouse anti-Border Disease virus p125/p80 IgG1 $\mathrm{mAb}$ and purified rabbit immunoglobulin (Sigma-Aldrich) for mouse and rabbit primary antibodies, respectively). All antibodies were diluted in PBS/T80 containing 10\% NGS. After washing, sections were incubated with the appropriate secondary antibody (peroxidase-labelled anti-mouse or anti-rabbit EnVision ${ }^{\text {тм }}+$ reagent; Dako) for $30 \mathrm{~min}$ at RT before developing with 3,3'-diaminobenzidine, counterstaining with haematoxylin, dehydrating and mounting in Shandon synthetic mountant (Thermo Fisher Scientific). For each run of IHC, a section of gastric lymph node was analyzed in parallel as a positive control. For dual fluorescence labeling of Foxp3 and CD3, following antigen retrieval and blocking, sections were incubated overnight at $4{ }^{\circ} \mathrm{C}$ with both $5 \mu \mathrm{g} / \mathrm{mL}$ mAbcam 22510 (Abcam) and $2 \mu \mathrm{g} / \mathrm{mL}$ polyclonal rabbit anti-human CD3 antibody or the appropriate controls (VPM21 and purified rabbit immunoglobulin). Sections were then incubated with horseradish peroxidase (HRP) labeled anti-mouse EnVision ${ }^{\mathrm{TM}}+$ reagent (Dako) for 30 min at RT and Foxp3 signal developed by incubation with Alexa Fluor ${ }^{\circledast} 488$ tyramide substrate (Invitrogen). Following washing, CD3 signal was developed by incubation with $2 \mu \mathrm{g} / \mathrm{mL}$ donkey anti-rabbit IgG $(\mathrm{H}+\mathrm{L})$ conjugated to Rhodamine Red-X (Jackson ImmunoResearch Laboratories Inc., West Grove, PA, USA) and slides mounted in Mowiol 4-88 (Calbiochem, Nottingham, UK). Cell counts were performed on single-labeled sections by counting the number of positive cells within the abomasal mucosa in 10 non-overlapping fields at $\times 20$ magnifications using a Leitz Dialux 20 light microscope (Leica Microsystems (UK) Ltd., Milton Keynes, UK) fitted with a $450 \times 450 \mu \mathrm{m}$ graticule. Counts were expressed as numbers of cells per $\mathrm{mm}^{2}$ of abomasal mucosa. To determine the proportion of $\mathrm{CD}^{+}$cells which were also Foxp $3^{+}$, dual fluorescent labeled slides were analyzed using an Axiovert 200M inverted fluorescence microscope equipped with an ApoTome slider module (Carl Zeiss Ltd., Welwyn Garden City, UK). A total of 500 $\mathrm{CD}^{+}$cells were analyzed per section and the number of cells which were double positive for CD3 and Foxp3 recorded. For publication purposes, images were captured using a Zeiss 710LSM confocal microscope (Carl Zeiss Ltd).

\section{Lymphocyte stimulation assays}

Blood was collected into EDTA-containing Vacutainers (BD, Franklin Lakes, NJ, USA) and PBMC isolated using a Ficoll-Paque $^{\mathrm{TM}}$ PLUS density gradient (GE Healthcare, Little Chalfont, UK) according to the manufacturer's instructions. PBMC were cultured in 96-well round- 
bottomed plates at $5 \times 10^{5}$ cells/well in RPMI 1640 (Invitrogen) containing $10 \%$ foetal calf serum (FCS), $2 \mathrm{mM}$ L-glutamine, $100 \mathrm{U} / \mathrm{mL}$ penicillin, $100 \mu \mathrm{g} / \mathrm{mL}$ streptomycin and $50 \mu \mathrm{M} 2$-mercaptoethanol at $37^{\circ} \mathrm{C} 5 \%$ $\mathrm{CO}_{2}$. To determine the effects of L4 ES products on mitogen-induced proliferation, $T$. circumcincta L4 ES products (Tci-L4-ES) or an equivalent volume of PBS were added for $30 \mathrm{~min}$ followed by addition of $5 \mu \mathrm{g} / \mathrm{mL}$ Concanavalin A (Con A, Sigma-Aldrich). Tci-L4-ES that had been previously heat-treated for $30 \mathrm{~min}$ at $100{ }^{\circ} \mathrm{C}$ was used as a control in initial experiments. These heattreatment conditions have been previously been reported for nematode ES products [15] and were used to ensured complete denaturation of protein components within the ES. After $72 \mathrm{~h}$, cells were harvested for flow cytometric analysis or for preparation of RNA for subsequent quantitative PCR analysis. In some experiments, naïve $\mathrm{CD} 4^{+} \mathrm{CD} 25^{-} \mathrm{CD} 45 \mathrm{RA}^{+} \mathrm{T}$ cells plus irradiated autologous antigen-presenting cells were used instead of PBMC. For time course studies, cells were also harvested at $0,24,48$ and $72 \mathrm{~h}$ post-stimulation for flow cytometry analysis. Cell proliferation was measured by incorporation of methyl-3H-thymidine $\left(\left[{ }^{3} \mathrm{H}\right]\right.$ thymidine, $0.5 \mu \mathrm{Ci}$ per well; GE Healthcare) for the final $18 \mathrm{~h}$ of culture, after which cells were harvested onto glassfibre filters (Perkin-Elmer, Cambridge, UK) and counted in a Wallac 1450 MicroBeta ${ }^{\bullet}$ TriLux Microplate Scintillation and Luminescence Counter (Perkin-Elmer). Proliferation results were expressed as counts per minute (cpm). In some experiments, cell-free culture supernatants were harvested at $54 \mathrm{~h}$ of culture and stored at $-70{ }^{\circ} \mathrm{C}$ for subsequent cytokine ELISAs.

To exclude possible apoptotic and/or necrotic effects, cells were also assessed in some cultures at $72 \mathrm{~h}$ using both an Annexin V APC apoptosis detection kit (BD Pharmingen $^{\mathrm{Tm}}$, San Diego, CA, USA), in which Annexin $\mathrm{V}+/ 7 \mathrm{AAD}$ - labeling indicates early apoptosis and Annexin V+/7AAD+ labeling indicates either late apoptosis or necrosis, and a Caspase 3 activity assay kit (Roche Applied Science, Burgess Hill, UK), according to the manufacturers' instructions.

To determine the role of interleukin-10 (IL-10) PBMC were cultured in the presence of $5 \mu \mathrm{g} / \mathrm{mL}$ anti-ovine IL10 monoclonal antibody (mAb) CC320 (AbDserotec, Kidlington, UK) or $5 \mu \mathrm{g} / \mathrm{mL}$ mouse IgG1 isotype control (eBioscience). To determine the effects of Tci-L4-ES on antigen-specific lymphocyte proliferation, PBMC were cultured as described above with $10 \mu \mathrm{g} / \mathrm{mL}$ lowendotoxin ovalbumin (EndoGrade ${ }^{\bullet}$ Ovalbumin, Hyglos $\mathrm{GmbH}$ ) in the presence or absence of $30 \mu \mathrm{g} / \mathrm{mL} \mathrm{Tci-L4-}$ ES. Proliferation was assessed after 5 days of culture by the measurement of methyl-3H-thymidine incorporation. To determine proliferation and IL-10 release in response to ES antigens, PBMC were incubated with
$30 \mu \mathrm{g} / \mathrm{mL}$ heat-inactivated Tci-L4-ES and culture supernatants were harvested at $54 \mathrm{~h}$ and proliferation assessed at $72 \mathrm{~h}$. Proliferation results were expressed as a Stimulation index (SI) which was calculated as the cpm of Tci-L4-HiES stimulated PBMC divided by the cpm of unstimulated control PBMC.

\section{Flow cytometry and fluorescence-activated cell sorting (FACS)}

Triple labeling of PBMC for CD4, CD25 and Foxp3 was performed using the following monoclonal antibodies (mAb): $1 \mu \mathrm{g} / \mathrm{mL}$ anti-ovine CD4 conjugated to FITC (clone 44.38, mouse IgG2a, AbDserotec), $2 \mu \mathrm{g} / \mathrm{mL}$ antiovine CD25 conjugated to R-phycoerythrin (RPE) (clone ILA111, mouse IgG1, AbDserotec), $2.5 \mu \mathrm{g} / \mathrm{mL}$ antimouse/rat Foxp3 conjugated to Alexa Fluor 647 or RPE-Cy7 (clone FJK-16s, rat IgG2a, eBioscience), or the appropriate isotype controls, as previously described [22]. Briefly, cells were incubated with anti-ovine CD4FITC and anti-ovine CD25-RPE in FACS buffer (PBS + $5 \%$ FCS) for $30 \mathrm{~min}$ at $4{ }^{\circ} \mathrm{C}$, then fixed in $1 \%$ paraformaldehyde in PBS for $10 \mathrm{~min}$ at room temperature (RT). Following fixation, cells were permeabilised overnight at $4{ }^{\circ} \mathrm{C}$ in FACS buffer containing $0.2 \%$ saponin (SigmaAldrich) and 20\% normal rat serum. Cells were then incubated with anti-mouse/rat Foxp3 antibody in FACS buffer for $1 \mathrm{~h}$ at $4{ }^{\circ} \mathrm{C}$ and fixed again in $1 \%$ paraformaldehyde in PBS for $10 \mathrm{~min}$ prior to analysis. For each experiment, previously generated Chinese hamster ovary cells transfected with ovine Foxp3 were labeled in parallel as a positive control for Foxp3 staining. Cells were analysed on a $\mathrm{Cyan}^{\mathrm{Tm}}$ ADP flow cytometer (Beckman Coulter Inc., Fullerton, CA, USA) using the manufacturer's acquisition software (Summit version 4.3). Cells were gated on the basis of their physical characteristics (forward and side scatter) to exclude debris and damaged cells. For FACS sorting of naïve $\mathrm{CD} 4^{+} \mathrm{T}$ cells, PBMC were labeled with anti-ovine CD45RA (clone 73B, mouse IgG1 [23]) followed by anti-mouse IgG1 conjugated to Alexa Fluor 647 (Invitrogen) and then blocked in 20\% normal mouse serum before incubating with anti-ovine CD4-FITC and anti-ovine CD25-RPE. Naïve $\mathrm{CD} 4^{+} \mathrm{CD} 25^{-} \mathrm{CD} 45 \mathrm{RA}^{+}$cells were sorted using a BD FACSAria $^{\text {Th }}$ IIIu cell sorter (BD Biosciences, San Jose, CA, USA), obtaining $\sim 88 \%$ purity. $\mathrm{CD}^{-} \mathrm{CD}^{-} 5 \mathrm{RA}^{+}$cells were also collected for use as a source of antigen presenting cells in lymphocyte stimulation assays. Analysis of flow cytometry data was performed using FlowJo version 7.6.1 analysis software (TreeStar, San Carlos, CA, USA).

\section{Quantative RT-PCR analysis}

RNA was prepared from cells using an RNeasy Plus kit (Qiagen) which included removal of genomic DNA using a gDNA eliminator column (Qiagen). Relative quantification 
of gene transcription by two-step, quantitative RT-PCR was performed for IL-4, IL-10, interferon-gamma (IFN- $\gamma$ ) and TGF- $\beta 1$ using the standard curve method and GAPDH for normalization purposes with modifications $[24,25]$. Briefly, first strand cDNA was synthesized using Superscript $^{\mathrm{TM}}$ II (Invitrogen) and oligo(dT) primers (SigmaAldrich) according to the manufacturer's instructions. Real-time RT-PCR was performed using an ABI Prism 7000 real-time thermal cycler (Applied Biosystems, Foster City, CA, USA) and the appropriate primer sets (Table 1). Cycling was performed in $25 \mu \mathrm{L}$ reaction volumes using 1 $\mu \mathrm{L}$ cDNA, $12.5 \mu \mathrm{L}$ of SYBR ${ }^{\oplus}$ GREEN ER ${ }^{\mathrm{TM}}$ qPCR Supermix (Invitrogen) and $0.2 \mu \mathrm{M}$ of each primer. A no-template (negative) control was also included in each assay. Thermal cycling parameters involved a 10 min pre-incubation step at $95{ }^{\circ} \mathrm{C}$ followed by 40 cycles of $95{ }^{\circ} \mathrm{C}$ for $30 \mathrm{~s}, 55^{\circ} \mathrm{C}$ for $30 \mathrm{~s}$ and $72{ }^{\circ} \mathrm{C}$ for $30 \mathrm{~s}$. Fluorescence data acquisition was performed after each cycle and melting curve analysis performed at the end of each run to verify the specificity of each PCR product. Serial, 10-fold dilutions (from $10^{2}$ to $10^{8}$ copies per $\mu \mathrm{L}$ ) of previously constructed plasmids containing the relevant gene (IL-4 [26], IFN- $\gamma$ [27], IL-10 and TGF- $\beta 1$ [25]) were amplified in parallel with each series of samples, allowing the automatic generation of standard curves using the Applied Biosystems 7000 System SDS software. The number of copies per $\mu \mathrm{L}$ of cDNA was then calculated and the results normalized to GAPDH.

\section{Quantification of $T$. circumcincta ES-specific antibodies by ELISA}

Tci-L4-ES-specific IgA and IgG were quantified in serum by indirect ELISA as follows: Microtitre plates were coated overnight at $4{ }^{\circ} \mathrm{C}$ with $5 \mu \mathrm{g} / \mathrm{mL}$ Tci-L4-ES in 0.1 $\mathrm{M}$ carbonate buffer $\mathrm{pH}$ 9.6. After washing in PBS, $\mathrm{pH}$ 7.4 , containing $0.05 \%$ Tween $20^{\circ}$ (PBS/T), non-specific binding sites were blocked with Tris-buffered saline (TBS) containing $0.05 \%$ Tween $20^{\circ}$ (TBST) and 5\% soya milk powder. Plates were subsequently incubated for $1 \mathrm{~h}$ at RT with serum diluted 1:10 for IgA and 1:1000 for IgG in TBST. For each plate, 8 wells were incubated with buffer alone and a known positive control sample was analyzed. After washing, plates were incubated for $1 \mathrm{~h}$ at RT with a 1:250 dilution of mouse anti-ovine/ bovine IgA (clone K84 2F9, AbDSerotec) or at 1:1000 dilution of anti-sheep/goat IgG-HRP (clone GT-34, Sigma Aldrich) for IgA and IgG ELISAs, respectively. For IgA ELISAs, plates were subsequently incubated with a 1:1000 dilution of rabbit anti-mouse IgG-HRP (Dako). After a final wash in $\mathrm{PBS} / \mathrm{T}$, colour reactions were developed by addition of Sigma-Fast OPD substrate (SigmaAldrich). Reactions were terminated after 5-10 min by addition of $2.5 \mathrm{M} \mathrm{H}_{2} \mathrm{SO}_{4}$, and the $\mathrm{OD}$ at $492 \mathrm{~nm}$ measured using a Sunrise ${ }^{\mathrm{TM}}$ microplate reader (Tecan, Männedorf, $\mathrm{CH}$, Switzerland).

\section{Quantification of interferon-gamma (IFN- $\gamma$ ), interleukin-4 (IL-4) and IL-10 by ELISA}

IFN- $\gamma$ was quantified using a commercial ELISA kit according to the manufacturer's instructions (MABTECH $\mathrm{AB}$, Augustendalsvägen, SE, Sweden) and expressed as $\mathrm{pg} / \mathrm{mL}$. IL-4 and IL-10 were quantified using paired antibodies (AbD Serotec) and established protocols as previously described [29,30]. Quantification was performed using recombinant ovine IL-10 or ovine IL-4 expressed in Chinese Hamster Ovary $(\mathrm{CHO})$ cells using the pEE14 expression vector (Lonza ) according to a previously published protocol [31]. ELISA values were related back to the known biological activity of the cytokines to enable cytokine quantification. IL-4 quantities were expressed as pg/mL and IL-10 quantities expressed as biological units (bU)/mL.

\section{Statistical analyses}

Data was analysed using GraphPad Prism version 5.01. Data were log transformed as required to ensure that observations within each group had an approximately normal distribution with a common variance. Subsequent

Table 1 Primer sequences and annealing temperatures for real-time PCR assays.

\begin{tabular}{|c|c|c|c|}
\hline Gene & Genbank accession no. & Primer sequence $\left(5^{\prime}-3^{\prime}\right)$ & $T_{\text {ANN }}\left({ }^{\circ} \mathrm{C}\right)$ \\
\hline \multirow[t]{2}{*}{ GAPDH [25] } & AF030943 & F: GGT GAT GCT GGT GCT GAG TA & 57 \\
\hline & & R: TCA TAA GTC CCT CCA CGA TG & \\
\hline \multirow[t]{2}{*}{ IL-4 [28] } & AF172168 & F: AGA GAT CAT CAA AAC GCT GAA & 55 \\
\hline & & R: GTC TGC TAC AGG CAG CTC & \\
\hline \multirow[t]{2}{*}{ IL-10 [25] } & NM_001009327 & F: TGA AGG ACC AAC TGA ACA GC & 55 \\
\hline & & R: TTC ACG TGC TCC TTG ATG TC & \\
\hline \multirow[t]{2}{*}{ TGF- $\beta 1[25]$} & NM_001009400 & F: GAA CTG CTG TGT TCG TCA GC & 55 \\
\hline & & R: GGT TGT GCT GGT TGT ACA GG & \\
\hline \multirow[t]{2}{*}{ IFN- $\gamma[27]$} & NM_001009803 & F: CTA AGG GTG GGC CTC TाT TC & 55 \\
\hline & & R:CAT CCA CCG GAA TTा GAA TC & \\
\hline
\end{tabular}

$T_{\text {ANN }}=$ primer annealing temperature . 
analysis was performed using one-way ANOVA followed by the Tukey post hoc test for pairwise comparison of means with the exception of data obtained from repeated PBMC cultures from the same animals, which were analysed using repeated-measures two-way ANOVA followed by the Bonferroni post hoc test for comparison of means where data was obtained at multiple time points, or a paired students $t$-test where only two time points were analysed. $P$ values of $<0.05$ were considered significant.

\section{Results}

Primary infection with $T$. circumcincta results in recruitment of Foxp $3^{+}$T cells into the abomasal mucosa

To determine whether Foxp $3^{+} \mathrm{T}$ cell levels increase locally during early infection, helminth-free lambs were challenged with a single infection of $50000 \mathrm{~T}$. circumcincta L3 and the numbers and location of Foxp $3^{+} \mathrm{T}$ cells within the abomasal mucosa determined at 0,5 and 10 days postchallenge by IHC. Representative IHC labeling is shown in Figure 1A-D, and cell count data shown in Figure 1E-F. A significant increase in numbers of abomasal mucosal Foxp $3^{+}$cells was observed at $10 \mathrm{dpi}(P<0.001$, Figure $1 \mathrm{E})$. Positive cells were often present in clusters adjacent to, but not in direct contact with, mucosal stage larvae (Figure 1A). The increase in Foxp $3^{+}$cells mirrored the increase in abomasal $\mathrm{CD}^{+} \mathrm{T}$ cell numbers, which were also significantly increased at $10 \mathrm{dpi}(P<0.05$, Figure $1 \mathrm{~F})$. The proportion of abomasal $\mathrm{T}$ cells expressing Foxp3, as determined by double IHC labeling of CD3 and Foxp3, did not change significantly over the 10-day period (Figure 1G). Furthermore, all Foxp $3^{+}$cells within the abomasal mucosa were also $\mathrm{CD}^{+}$, confirming their identity as T cells.

\section{T. circumcincta L4 ES products inhibit ovine lymphocyte activation in vitro}

Having shown that abomasal Foxp $3^{+} \mathrm{T}$ cells numbers increase by $10 \mathrm{dpi}$, a time at which most $T$. circumcincta would be at L4 stage in the gastric gland [32], we determined whether Tci-L4-ES products were capable of inducing expression of Foxp3 in activated ovine CD4 ${ }^{+}$ lymphocytes, as has been previously shown in murine $\mathrm{CD}^{+}$cells [15]. PBMC cultures from helminth-naïve lambs were stimulated with the $\mathrm{T}$ cell mitogen Con $\mathrm{A}$ in the presence or absence of $30 \mu \mathrm{g} / \mathrm{mL} \mathrm{Tci-L4-ES} \mathrm{for} 72 \mathrm{~h}$, an identical ES concentration and time-point to that used in the murine study [15], and the number of cells expressing Foxp3 and the T cell activation marker CD25 (IL-2R $\alpha$-chain) determined by flow cytometry. As Foxp3 is preferentially expressed by $\mathrm{CD} 4{ }^{+} \mathrm{CD} 25^{+} \mathrm{T}$ cells [22], Foxp3 expression was determined in both $\mathrm{CD} 4^{+}$and $\mathrm{CD} 4^{+} \mathrm{CD} 25^{+}$subpopulations. Results are shown in Figure 2. No increase in the proportion of cells expressing Foxp3 within the total $\mathrm{PBMC}, \mathrm{CD} 4^{+}$or $\mathrm{CD} 4^{+} \mathrm{CD} 25^{+}$populations was observed following incubation with Tci-L4-ES; however, incubation with Tci-L4-ES resulted in a significant decrease in the proportion of cells expressing $\mathrm{CD} 25$ in both $\mathrm{CD}^{+}$and total PBMC populations compared to cultures incubated with Con $\mathrm{A}$ alone. This effect was heat labile, as heat-inactivated Tci-L4-ES had no effect on the proportion of cells expressing CD25 in Con A-stimulated cultures. These results suggested that TciL4-ES was inhibiting mitogen-induced T cell activation.

To investigate the potential effects of Tci-L4-ES on lymphocyte activation further, we determined the level of cell proliferation in Con A and Con A + ES stimulated cultures at $72 \mathrm{~h}$ by incorporation of $\left[{ }^{3} \mathrm{H}\right]$ thymidine. Addition of $30 \mu \mathrm{g} / \mathrm{mL}$ Tci-L4-ES to Con A-stimulated cultures resulted in a highly significant (between $85-90 \%$ ) reduction in cell proliferation compared to cultures stimulated with Con A alone ( $P<0.001$, Figure 3A). This suppressive effect occurred over a range of Tci-L4-ES concentrations, and still occurred at $3.75 \mu \mathrm{g} / \mathrm{mL}$ Tci-L4-ES (Figure 3B). Again, the effect was heat-labile (Figure 3A). Removal of LPS from Tci-L4-ES had no significant effect on the degree of suppression (see Additional file 1). No significant differences in caspase 3 activity were detected between ConA + ES stimulated cultures compared to all other cultures (Figure 3C), whereas the proportions of annexin $\mathrm{V}^{+} / 7 \mathrm{AAD}^{+}$cells was significantly lower and annexin $\mathrm{V}^{-} / 7 \mathrm{AAD}^{-}$cells significantly higher in ConA + ES stimulated cultures compared to all other cultures (Figure 3D), indicating that suppression of Con A-induced proliferation by Tci-L4-ES was not associated with increased apoptosis or necrosis.

To determine whether Tci-L4-ES was similarly capable of suppressing antigen-specific lymphocyte proliferation, PBMC obtained from three sheep previously immunized with ovalbumin were cultured with ovalbumin in the presence or absence of $30 \mu \mathrm{g} / \mathrm{mL}$ Tci-L4-ES and cell proliferation determined after 5 days of culture. Con $\mathrm{A}$ and Con A + ES stimulated cultures were also included as controls. Addition of Tci-L4-ES resulted in a significant (between 12$46 \%)$ reduction in antigen-specific proliferation $(P<0.05$, Figure $3 \mathrm{E}$ ), and the relative degree of ES-mediated suppression was similar in both antigen and Con A-stimulated cultures. The suppressive effects were again heat-labile. The level of suppression of Con A stimulated cultures (31-40\% reduction in proliferation) was far less than that observed in the previous experiments where we used helminth-free lambs: it was subsequently identified that all ovalbuminimmunized lambs harbored patent $T$. circumcincta infections as determined by species-specific PCR using DNA derived from eggs harvested from their faeces.

\section{Lack of induction of Foxp3 expression in ovine CD4 ${ }^{+} \mathrm{T}$ cells by $T$. circumcincta L4 ES in vitro}

The lack of observable increase in\% Foxp3 expression in the $\mathrm{CD}^{+}$population in the previous experiments was in 

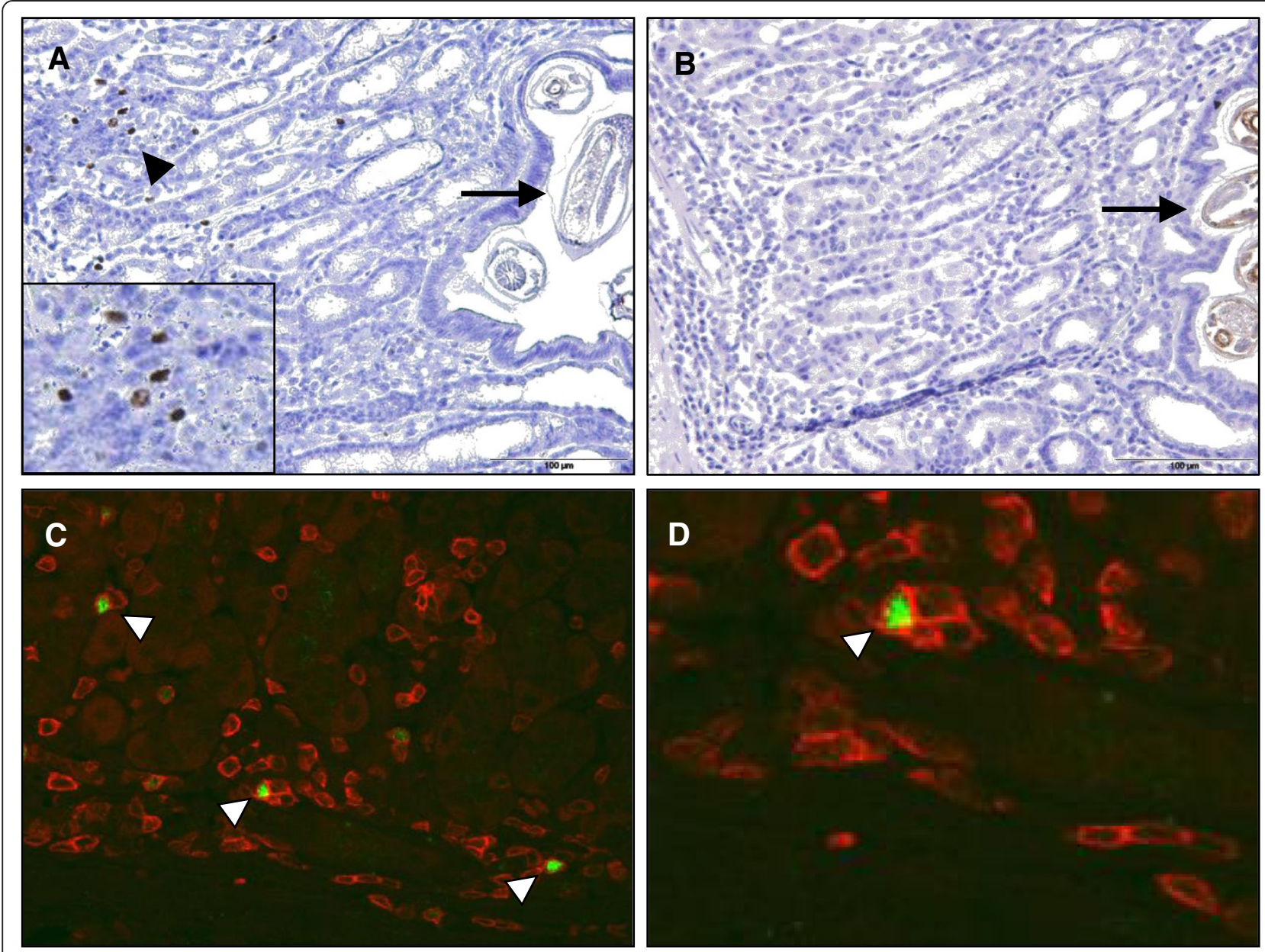

E

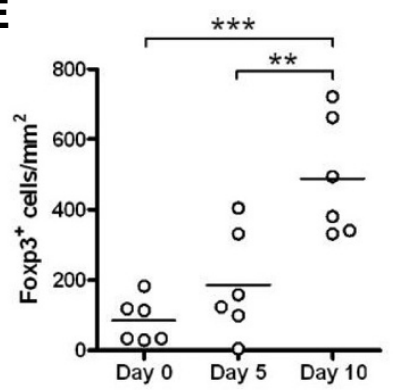

$\mathbf{F}$

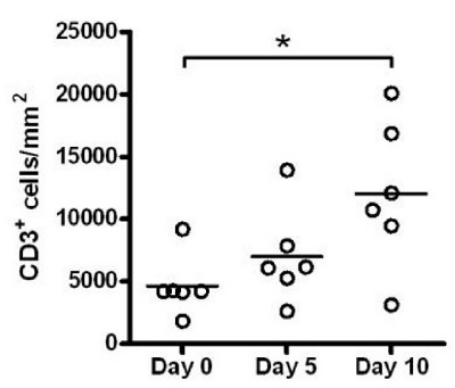

G

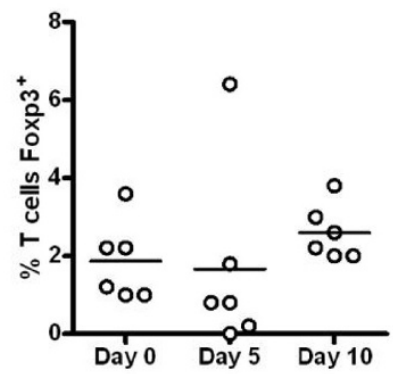

Figure 1 Immunohistochemical identification of Foxp $3^{+} \mathrm{T}$ cells within the abomasal mucosa during infection with $T$. circumcincta. (A) Single immunohistochemical (IHC) labeling of Foxp3 demonstrating a number of positive cells within the abomasal mucosa at $10 \mathrm{dpi}$ (arrowhead). A high-power view of Foxp ${ }^{+}$cells is inset in the panel. The arrow indicates a T. circumcincta larva within the mucosa. (B) Isotype control. (C) Double IHC labeling of Foxp3 (green) and CD3 (red) in the abomasal mucosa at 10 dpi. Arrowheads indicate double positive cells. (D) High-power view of panel $\mathrm{C}$ demonstrating surface labeling of CD3 and nuclear labeling of Foxp3. (E) Numbers of Foxp3 ${ }^{+}$cells within the abomasal mucosa at 0,5 and 10 dpi. (F) Numbers of $\mathrm{CD}^{+}$cells within the abomasal mucosa at 0,5 and 10 dpi. (G) The proportions of $\mathrm{CD}^{+} \mathrm{T}$ cells within the abomasal mucosa expressing Foxp3 at 0,5 and 10 dpi. ${ }^{*} P<0.05,{ }^{*} P<0.01,{ }^{* *} P<0.001$ (one way ANOVA followed by the Tukey post hoc test for pairwise comparison of means). Panel (A) has been previously presented by the authors [9]. 

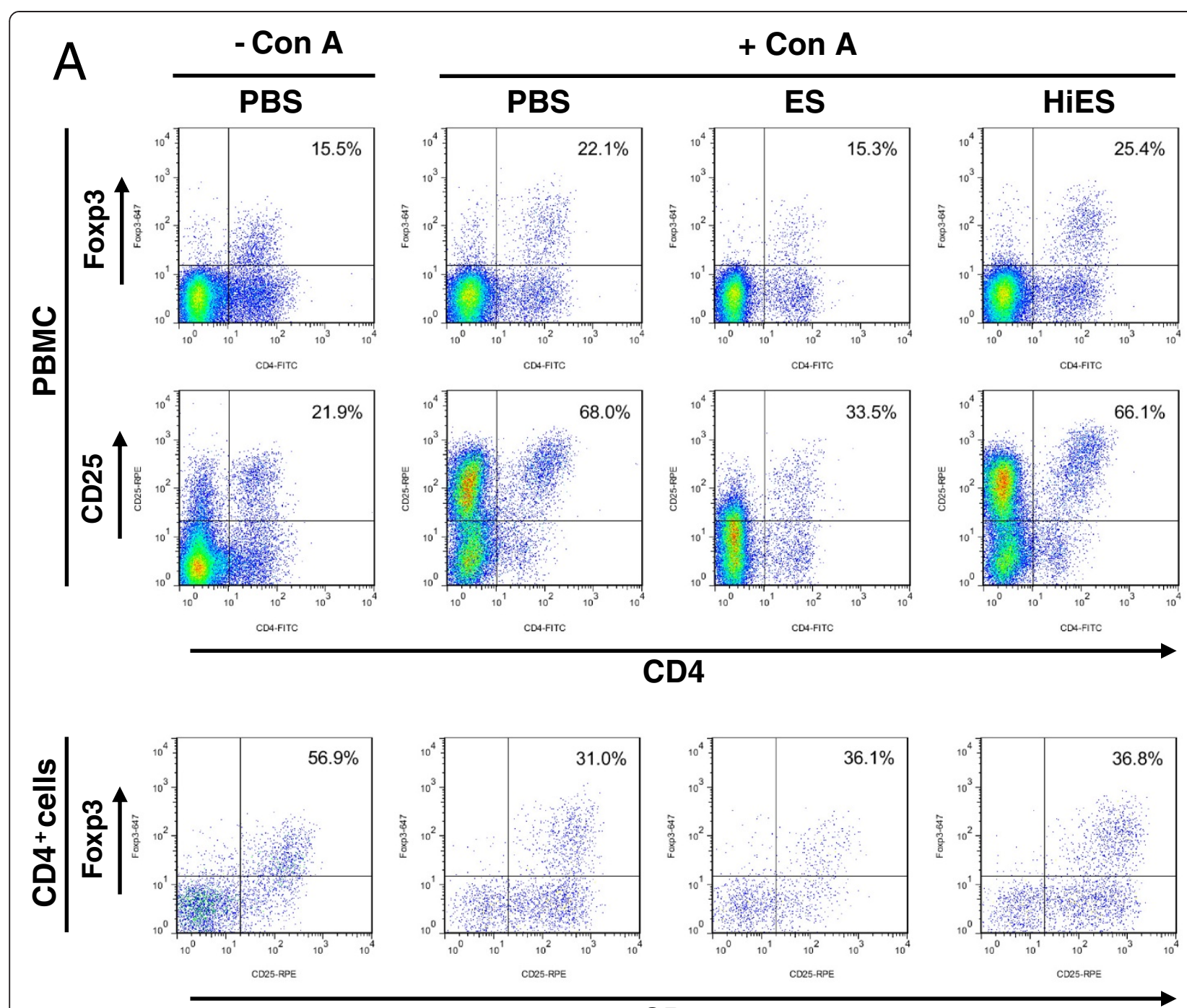

\section{CD25}

B
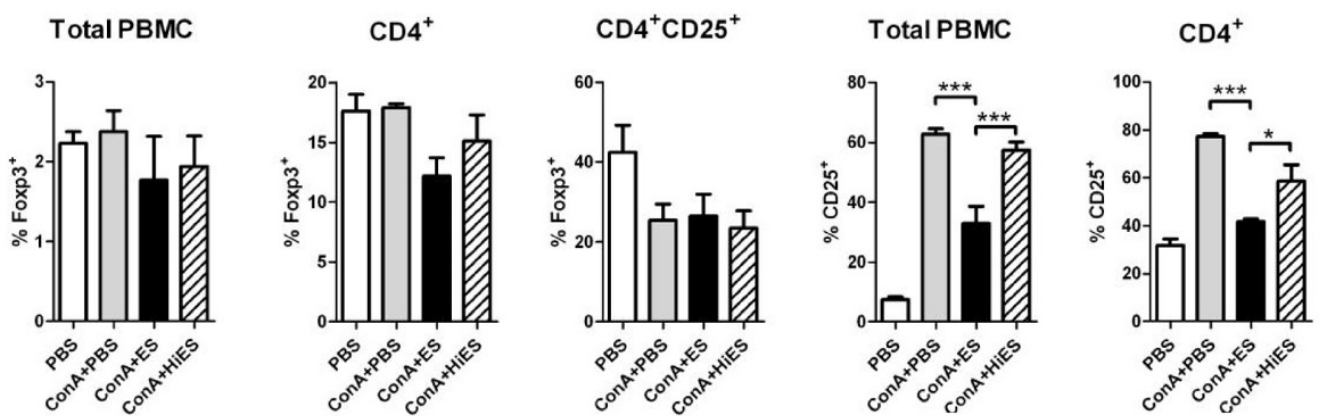

Figure 2 Expression of Foxp3 and CD25 by CD4 ${ }^{+}$T cells stimulated with Con A \pm Tci-L4-ES. (A) Representative plots of Foxp3 and CD25 expression by $\mathrm{CD}^{+} \mathrm{T}$ cells from PBMC from helminth-naïve lambs cultured for $72 \mathrm{~h}$ with PBS alone (PBS), $5 \mu \mathrm{g} / \mathrm{mL}$ Con A alone (ConA + PBS), 5 $\mu \mathrm{g} / \mathrm{mL}$ Con A $+30 \mu \mathrm{g} / \mathrm{mL}$ TCi-L4-ES (ConA + ES) or $5 \mu \mathrm{g} / \mathrm{mL}$ Con A + $30 \mu \mathrm{g} / \mathrm{mL}$ heat-inactivated Tci-L4-ES (ConA + HiES). Numbers indicate the percentage of $\mathrm{CD}^{+}$cells co-expressing Foxp3 (top panel) or CD25 (middle panel) and the percentage of CD4 $4^{+} \mathrm{CD} 25^{+}$cells co-expressing Foxp3 (lower panel). (B) Percentages of total PBMC, CD4 $4^{+}$cells and $C D 4^{+} C D 25^{+}$cells co-expressing Foxp3, and percentages of total PBMC and CD4 ${ }^{+}$ cells co-expressing CD25. Data represents mean \pm SEM from three replicate cultures from three helminth-free lambs. ${ }^{*} P<0.05,{ }^{* * *} P<0.001$ (one way ANOVA followed by the Tukey post hoc test for pairwise comparison of means). 

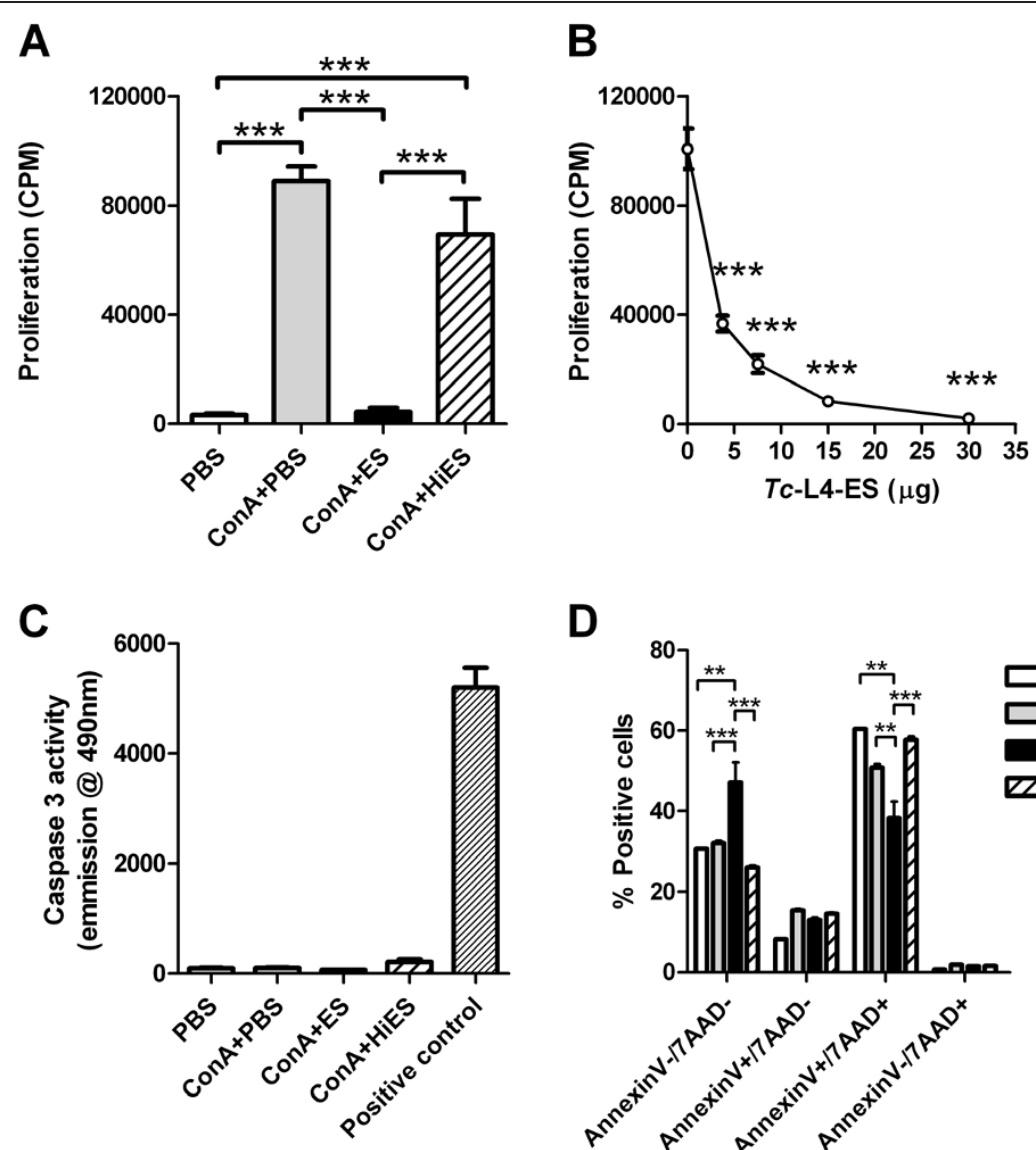

D
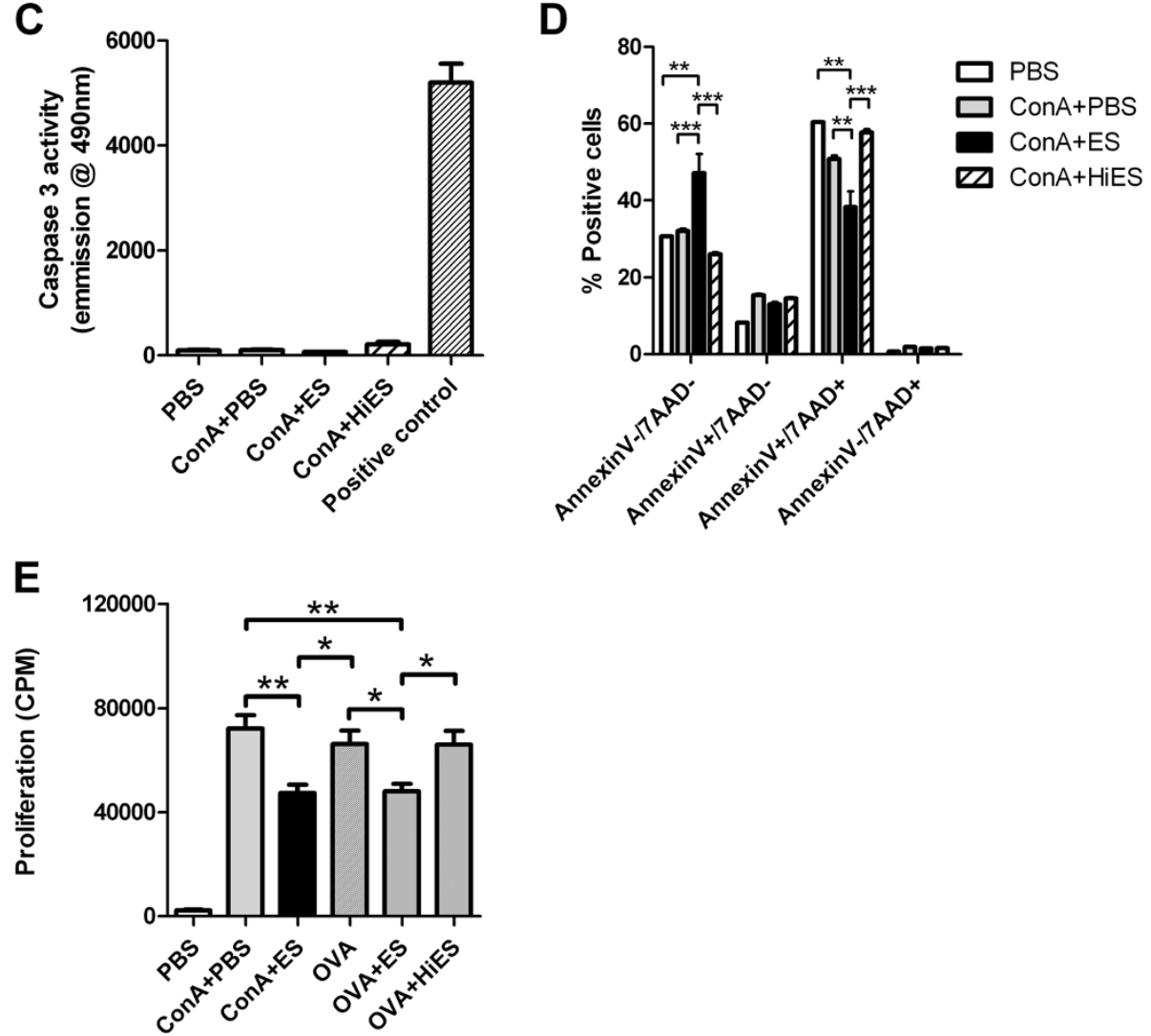

Figure 3 Suppression of mitogen-induced and antigen-specific lymphocyte proliferation by Tci-L4-ES. To determine the effects of TCi-L4ES on mitogen-induced proliferation, PBMC from helminth-naïve lambs were cultured with Con A in the presence or absence of TCi-L4-ES (ES) or heat-inactivated TCi-L4-ES (HiES). To determine the effects of TCi-L4-ES on antigen-specific proliferation, PBMC from ovalbumin (OVA)-immunized lambs were cultured with OVA in the presence or absence of ES or HiES. Proliferation assessed by incorporation of [3H] thymidine and expressed as counts per minute (cpm). (A) Proliferation of helminth-naïve PBMC at $72 \mathrm{~h}$ following culture with PBS alone (PBS), $5 \mu \mathrm{g} / \mathrm{mL}$ Con A (ConA + PBS), $5 \mu \mathrm{g} / \mathrm{mL}$ Con A $+30 \mu \mathrm{g} / \mathrm{mL}$ ES (ConA + ES) or $5 \mu \mathrm{g} / \mathrm{mL}$ Con A $+30 \mu \mathrm{g} / \mathrm{mL}$ HiES (ConA + HiES). (B) PBMC proliferation at $72 \mathrm{~h}$ following culture with $5 \mu \mathrm{g} / \mathrm{mL}$ Con A + 0, 3.75, 7.5, 15 and $30 \mu \mathrm{g} / \mathrm{mL}$ ES. (C-D) Caspase activity in PBMC cell lysates and Annexin V/7AAD staining in PBMC following $72 \mathrm{~h}$ culture with PBS, Con A, Con A + ES or Con A + HiES. (E) Proliferation of PBMC from ovalbumin-immunized lambs at $120 \mathrm{~h}$ following culture with PBS alone (PBS), $5 \mu \mathrm{g} / \mathrm{mL}$ Con A (ConA + PBS), $5 \mu \mathrm{g} / \mathrm{mL}$ Con A + 30 $\mu \mathrm{g} / \mathrm{mL}$ ES (ConA + ES), $10 \mu \mathrm{g} / \mathrm{mL} \mathrm{OVA} \mathrm{(OVA),} 10 \mu \mathrm{g} /$ $\mathrm{mL}$ OVA $+30 \mu \mathrm{g} / \mathrm{mL}$ ES (OVA + ES) or $10 \mu \mathrm{g} / \mathrm{mL}$ OVA $+30 \mu \mathrm{g} / \mathrm{mL}$ HiES (OVA + HiES). Data represents mean \pm SEM from three replicate cultures from three helminth-free lambs. ${ }^{*} P<0.05,{ }^{*} P<0.01,{ }^{* * *} P<0.001$ (one way ANOVA followed by the Tukey post hoc test for pairwise comparison of means). In panel (B) only significant differences between ES-treated and non-ES treated cultures are indicated. 
contrast to a previous study in mice which demonstrated that activation of $\mathrm{CD}^{+} \mathrm{T}$ cells in the presence of $30 \mu \mathrm{g} / \mathrm{mL}$ Tci-L4-ES resulted in an $\sim 20 \%$ increase in the proportion of $\mathrm{CD}^{+}{ }^{+} \mathrm{T}$ cells co-expressing Foxp3 by $72 \mathrm{~h}$ [15]. One possible reason for this discrepancy is that the dynamics of Foxp3 induction may be different between mice and sheep. We therefore performed a time-course experiment in which PBMC cultures were again stimulated with Con A and Tci-L4-ES and expression of Foxp3 determined at $0 \mathrm{~h}, 24 \mathrm{~h}, 48 \mathrm{~h}$ and $72 \mathrm{~h}$ by flow cytometry. The results are shown in Figure 4. No observable increase in the proportion of cells expressing Foxp3 was seen in Con A + ES stimulated cultures, either in the total PBMC population or the $\mathrm{CD}^{+}$population, compared to cultures incubated with Con $\mathrm{A}$ alone at any time-point (Figure 4A-B). As the induction of Foxp3 by Tci-L4-ES is thought to be due to the presence of parasite homologues of transforming growth factor- $\beta$ (TGF- $\beta 1$ ), a cytokine which preferentially induces Foxp3 expression in naïve rather than non-naive $\mathrm{CD}^{+} \mathrm{T}$ cells $[15,33]$, we also determined whether Tc-L4-ES was able to induce Foxp3 expression in purified naïve ovine $\mathrm{CD}^{+} \mathrm{T}$ cells. Naïve $\mathrm{CD}^{+} \mathrm{CD} 25^{-} \mathrm{CD} 45 \mathrm{RA}^{+} \mathrm{T}$ cells were stimulated with $30 \mu \mathrm{g} / \mathrm{mL}$ Tci-L4-ES in the presence of Con A and irradiated antigen-presenting cells and Foxp3 expression determined at $72 \mathrm{~h}$ by flow cytometry. Again, no increase in the proportion of cells expressing Foxp3 was observed in cultures stimulated with Con A + ES compared to Con A stimulation alone (see Additional file 2).

\section{Suppression of ovine lymphocyte activation by L4 ES} products is associated with up-regulation of IL-10 gene expression and involves the IL-10 signaling pathway Having identified profound immunosuppressive effects of Tci-L4-ES on ovine lymphocyte activation and proliferation, we next determined relative levels of transcription of

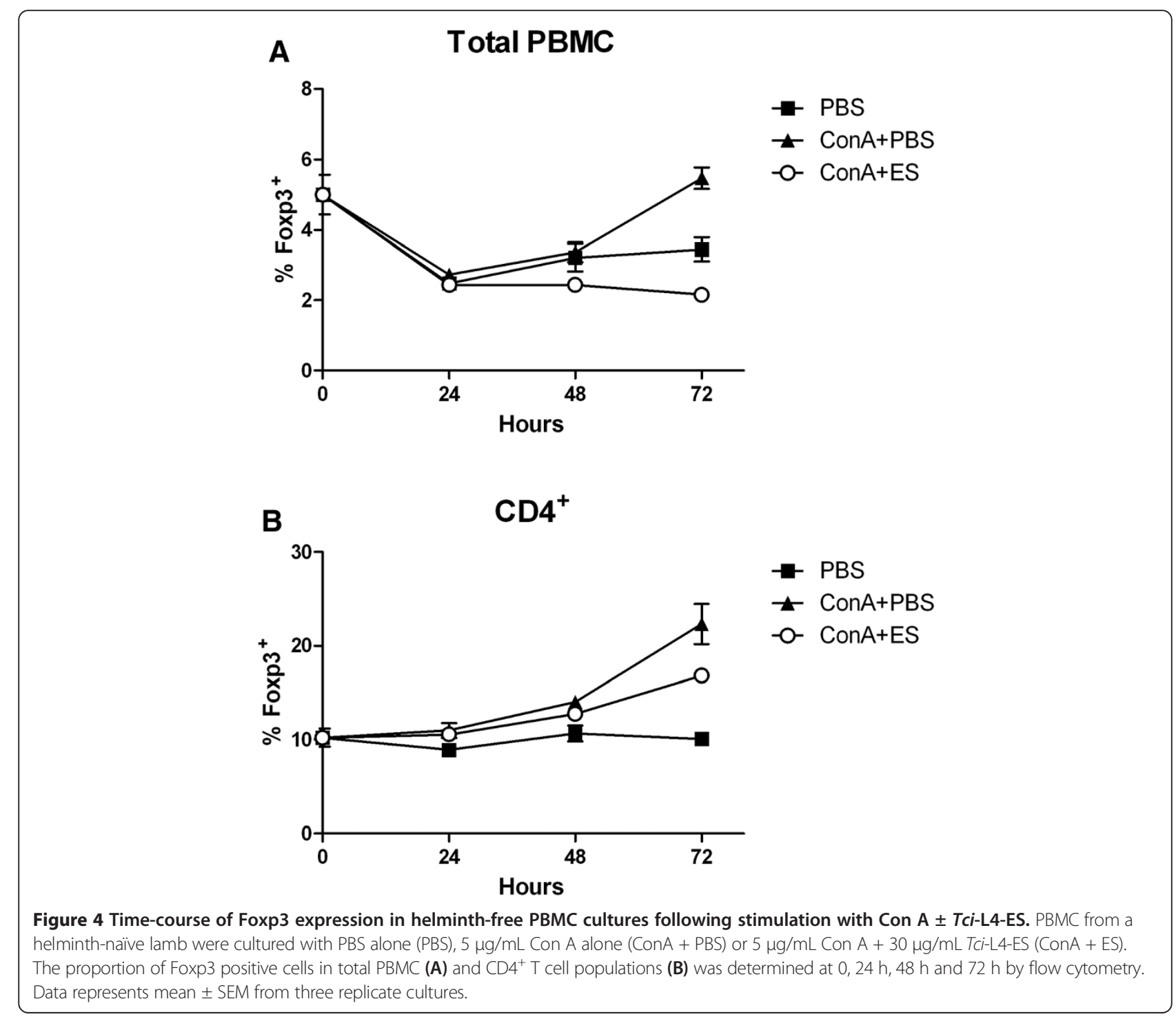


regulatory (IL-10, transforming growth factor- $\beta 1$ (TGF$\beta 1)$ ), Th-1 associated (IFN- $\gamma$ ) and Th-2 associated (IL-4) cytokines in Con A and Con A +ES stimulated PBMC after $72 \mathrm{~h}$ of culture by qRT-PCR. The results are shown in Figure 5. Stimulation of PBMC cultures with Con A + ES resulted in a significant increase in levels of IL-10 relative transcription compared to un-stimulated, Con A only-stimulated or Con A + heat-inactivated (Hi) ESstimulated PBMC $(P<0.0001$, Figure 5A). Levels of IL-4 transcript were significantly lower in Con A + ESstimulated PBMC compared to Con A-only stimulated PBMC $(P<0.01)$, but were not significantly different to that observed in Con A + Hi ES-stimulated PBMC (Figure 5C). No significant differences in transcript levels of TGF- $\beta 1$ or IFN- $\gamma$ were observed. These results indicate that Tci-L4-ES-mediated suppression of Con $\mathrm{A}$-induced lymphocyte activation was associated with an increase in PBMC IL-10 transcription.

To determine whether IL-10 signaling was involved in the observed effects, the impact of addition of the IL-10 neutralizing mAb, CC320 [34,35], on Tci-L4-ES-mediated suppression of Con A-induced proliferation was determined. The results are shown in Figure 6. Addition of IL-10 neutralising antibody resulted in a significant reduction in Tci-L4-ES-mediated suppression of ConAinduced proliferation, reducing the suppressive capacity of Tci-L4-ES by between 25 and 64\%. These results indicated that suppression of Con A-induced proliferation by Tci-L4-ES involves IL-10 signaling.

\section{L4 ES-mediated lymphocyte suppression declines following $T$. circumcincta challenge}

The results above indicate that Tci-L4-ES is profoundly suppressive of Con A-induced activation and proliferation of PBMC that are derived from helminth-naïve lambs. To investigate the effects of $T$. circumcincta infection on TciL4-ES mediated suppression of PBMC in vitro, seven helminth-naïve lambs were infected repeatedly over a four-week period with $T$. circumcincta and the suppressive capacity of Tci-L4-ES on Con A-induced proliferation of PBMC harvested at $0,2,4$ and 6 weeks from the start of infection (pi) determined. To confirm infection, FECs were recorded (Figure 7A). Proliferation of PBMC in response to Con A was consistent throughout the infection period at approximately $130000 \mathrm{cpm}$ (range = $127000-$ 137 000). In contrast, proliferation of PBMC in response to Con A + Tci-L4-ES increased from levels similar to unstimulated cultures at week $0(\sim 4000 \mathrm{cpm})$ to around $83000 \mathrm{cpm}$ by week 6 pi (Figure 7B). Expressed as a percentage suppression of Con A-induced PBMC proliferation in matched control wells, this equated to a reduction from $\sim 101 \%$ suppression at week 0 to $\sim 36 \%$ suppression by week 6 pi. This reduction in the suppressive capacity of Tci-L4-ES coincided with the appearance of Tci-L4-ESspecific IgA and IgG antibodies in serum (Figure 7C).

We also determined levels of IL-4, IFN- $\gamma$ and IL-10 in PBMC culture supernatants by ELISA. No significant differences in IL-4 secretion were observed between Con A, Con A + ES or un-stimulated cultures, although mean levels of IL-4 were always highest in Con A-stimulated cultures (Figure 7D). Similar IL-10 levels were observed in supernatants from Con A and Con A + ES stimulated cultures across all time-points and were greater than those observed in un-stimulated cultures. Across the sampling period, IL-10 levels remained similar at 0 and 2 week post infection (wpi), but increased in ConA + ES stimulated cultures at 4 and $6 \mathrm{wpi}$, and increased in Con Astimulated cultures at 6 wpi (Figure 7E). Significantly

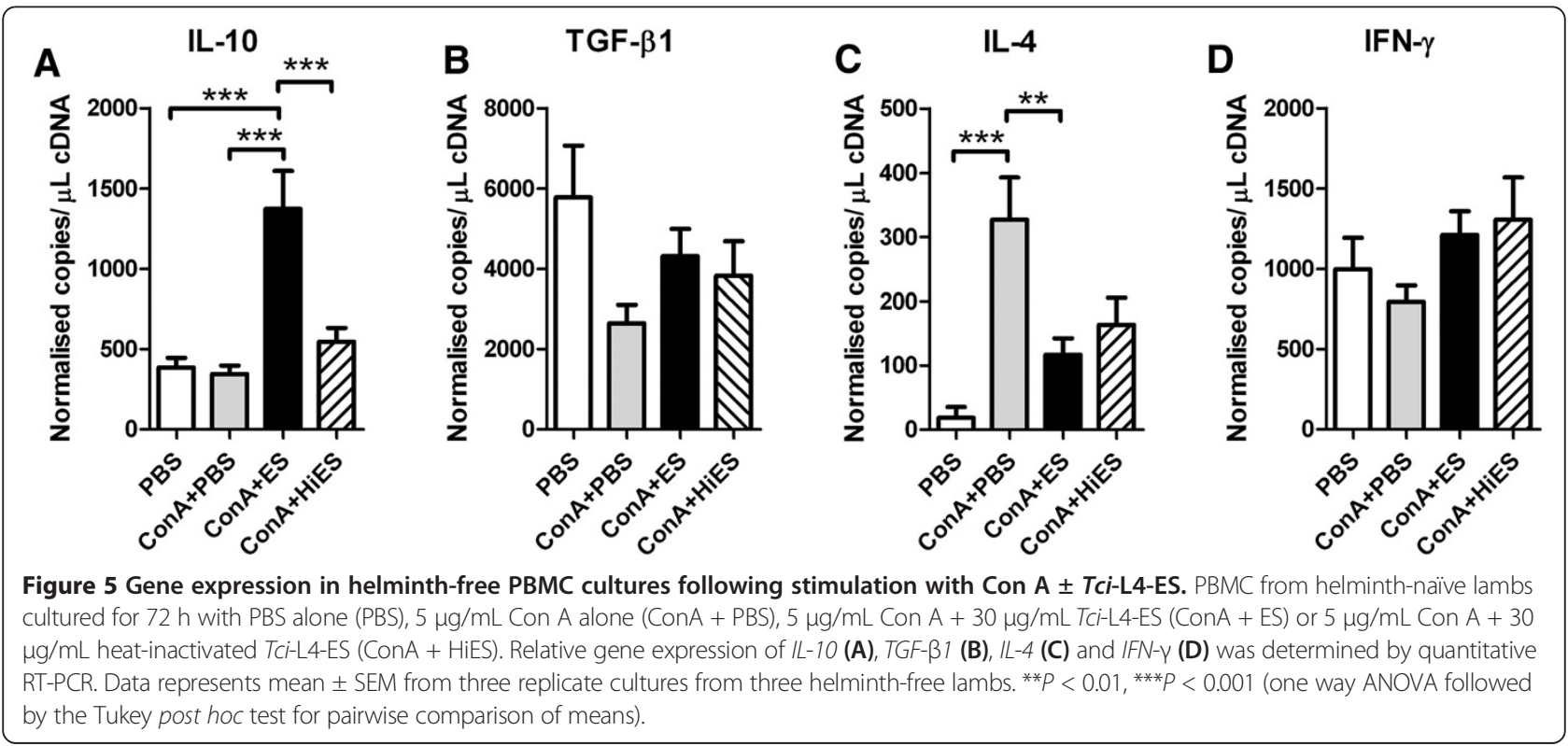




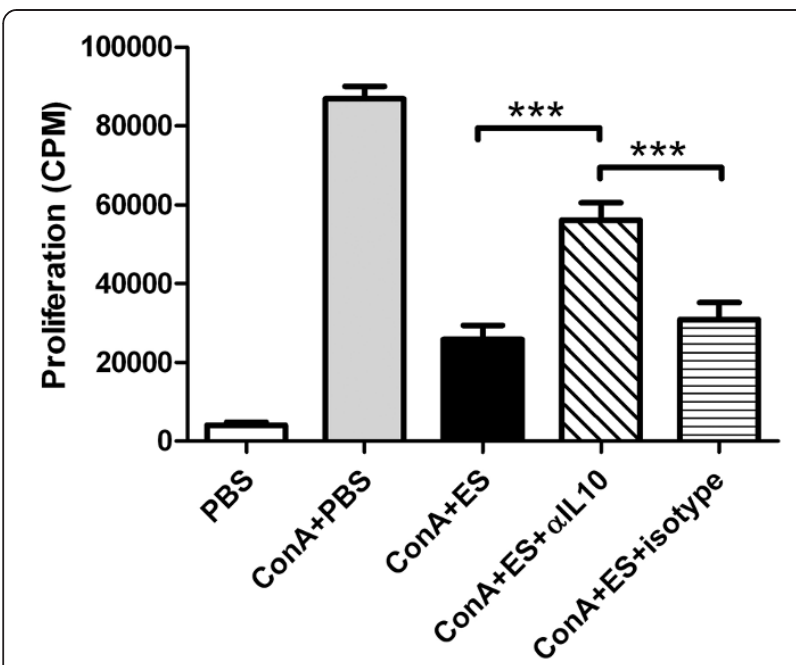

Figure 6 The effect of IL-10 neutralization on TCi-L4-ES mediated lymphocyte suppression. PBMC from helminth-naïve lambs were cultured with ConA $+15 \mu \mathrm{g} / \mathrm{mL}$ Tci-L4-ES in the presence or absence of $5 \mu \mathrm{g} / \mathrm{mL} \mathrm{IL}-10$ neutralizing mAb CC320 (ConA+ES+all10) or $5 \mu \mathrm{g} / \mathrm{mL}$ lgG1 isotype control $\mathrm{mAb}$ (ConA+ES+isotype). Proliferation was assessed after $72 \mathrm{~h}$ by measurement of $[3 \mathrm{H}]$ thymidine incorporation. Data represents mean \pm SEM from three replicate cultures from three helminth-free lambs. ${ }^{* *} P<0.001$ (one way ANOVA followed by the Tukey post hoc test for pairwise comparison of means).

higher levels of IFN- $\gamma$ were present in Con A stimulated cultures compared to Con A + ES stimulated cultures at 0 to 4 wpi, with IFN- $\gamma$ levels in Con A + ES-stimulated culture supernatants similar to those in un-stimulated cultures (Figure 7F). However, by 6 wpi, levels of IFN- $\gamma$ in Con Astimulated cultures had dropped and were no longer significantly different to those in ES or un-stimulated cultures.

One potential explanation for the reduced suppressive capacity of Tci-L4-ES on PBMC from T. circumcincta infected compared to helminth naïve lambs is that PBMC from infected lambs may contain increased numbers of Tci-L4-ES antigen-specific T cells which proliferate in response to antigens within Tci-L4-ES. To explore this further, five helminth-naïve lambs were repeatedly infected over a six-week period with T. circumcincta L3. PBMC were harvested immediately prior to infection and at $6 \mathrm{wpi}$ and both the suppressive capacity of TciL4-ES on ConA-induced proliferation and proliferation in response to heat-inactivated Tci-L4-ES was determined. ES was heat-inactivated in this experiment to abrogate the suppressive effects of native ES while at the same time providing a source of ES antigens for T cells. The results are shown in Figure 8. As in the previous experiment, Tci-L4-ES was less able to suppress PBMC from $T$. circumcincta infected lambs compared to PBMC obtained prior to infection (Figure 8A, $P<0.05$ ). This reduction in suppression of $\mathrm{PBMC}$ was associated with a significant increase in proliferation of $\mathrm{PBMC}$ in response to heat inactivated Tci-L4-ES antigen(s) (Figure 8B, $P<0.05$ ). Furthermore, IL-10 levels in the culture supernatants were significantly increased in PBMC cultures from infected vs. non-infected lambs following stimulation with both Con $\mathrm{A}+T c i$-L4-ES and heat-inactivated Tci-L4-ES (Figure 8C$\mathrm{D}$, both $P<0.05)$. Interestingly, PBMC from the lamb with the lowest decrease in ES-mediated suppression had the lowest increase in proliferation to heat-inactivated ES antigens, and also exhibited the lowest increase in IL-10 production following stimulation with ConA + ES or heatinactivated ES.

\section{Discussion}

Helminth infections are a major constraint to livestock production worldwide and represent a major challenge to continued food security. The parasitic nematodes that colonize the gastrointestinal tract of ruminants cause decreased appetite, reduced growth rate and persistent diarrhoea [36]. Virtually all ruminants grazing improved pastures are infected, either clinically or sub-clinically, with nematode members of the family Trichostrongylidae, of which $T$. circumcincta is the major genus found in sheep and goats in temperate areas. A feature of most gastrointestinal nematode infections is their chronicity, with poor immune responsiveness in young hosts [37] and/or parasite induced immune suppression [38] cited as major influences on the rate at which resistance to challenge develops. Because of the extensive nature of anthelmintic resistance, particularly in sheep nematodes [4], vaccines are being sought as alternatives for control. A major challenge to this research is the capability to design vaccines that are able to overcome the initial general lack of responsiveness to parasitic nematodes, particularly in young ruminants. This is concurrent with a time in life when producers are trying to maximize rates of growth. With this in mind, we have taken an approach to $T$. circumcincta vaccine development by investigating potential interactions between mucosal larvae and local effector responses. We have focused on larvae in the gastric gland (L4) because previous studies indicate that local humoral and cellular responses to these stages are critical in the initial acquisition of immunity in lambs $[10,12,39,40]$. Parasite ES products were targeted as they are the major interface between host and nematode. In studying the effect of Tci-L4-ES on lymphocytes, we have identified a novel mechanism by which this parasitic nematode appears to suppress lymphocyte activation and proliferation and hence may modulate the host adaptive immune response. This effect was particularly noticeable when we studied cells obtained from helminth naïve sheep and was reduced when we used cells derived from animals that were exposed to $T$. circumcincta infection, indicating that as animals develop immunity, the suppressive response associated with L4 ES components are reduced. 

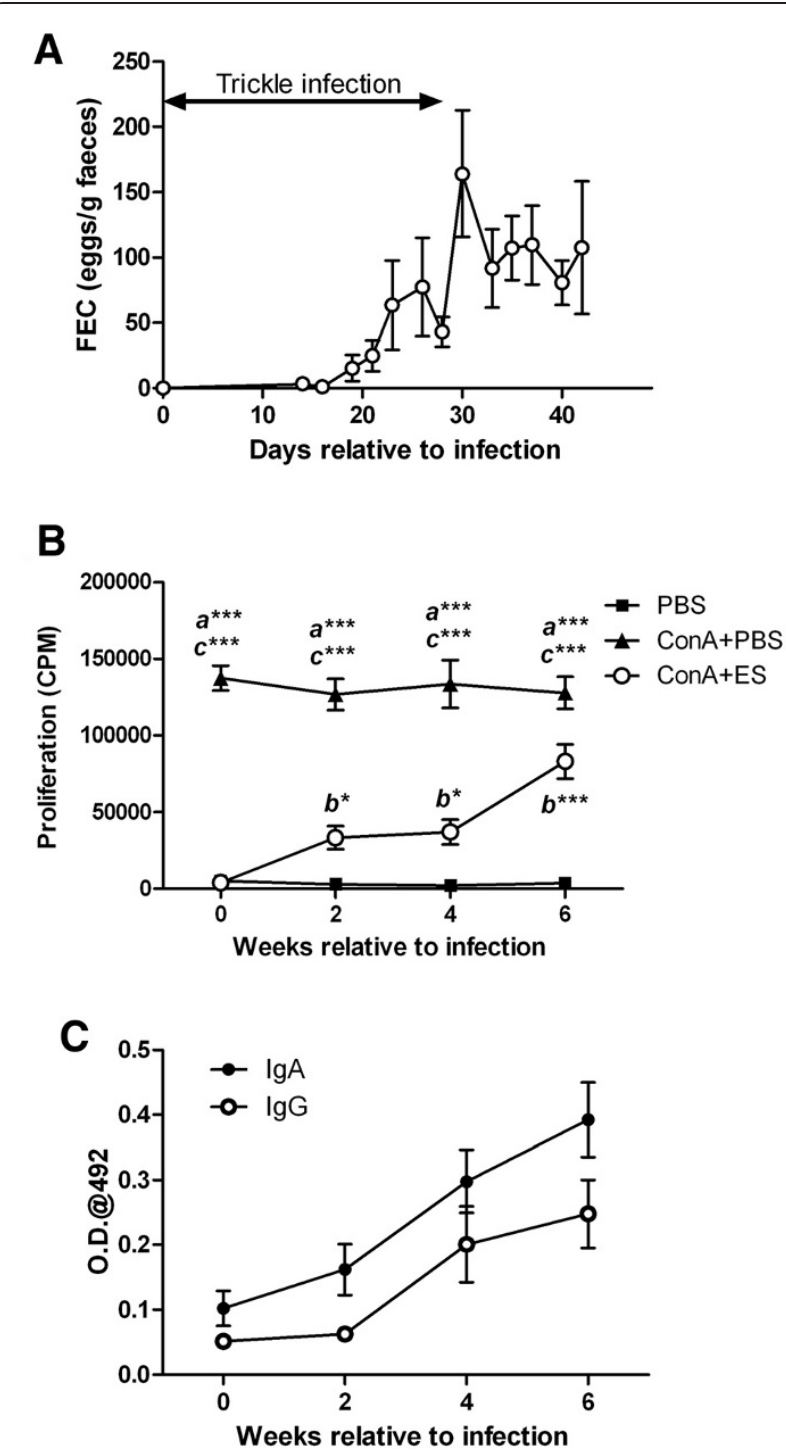
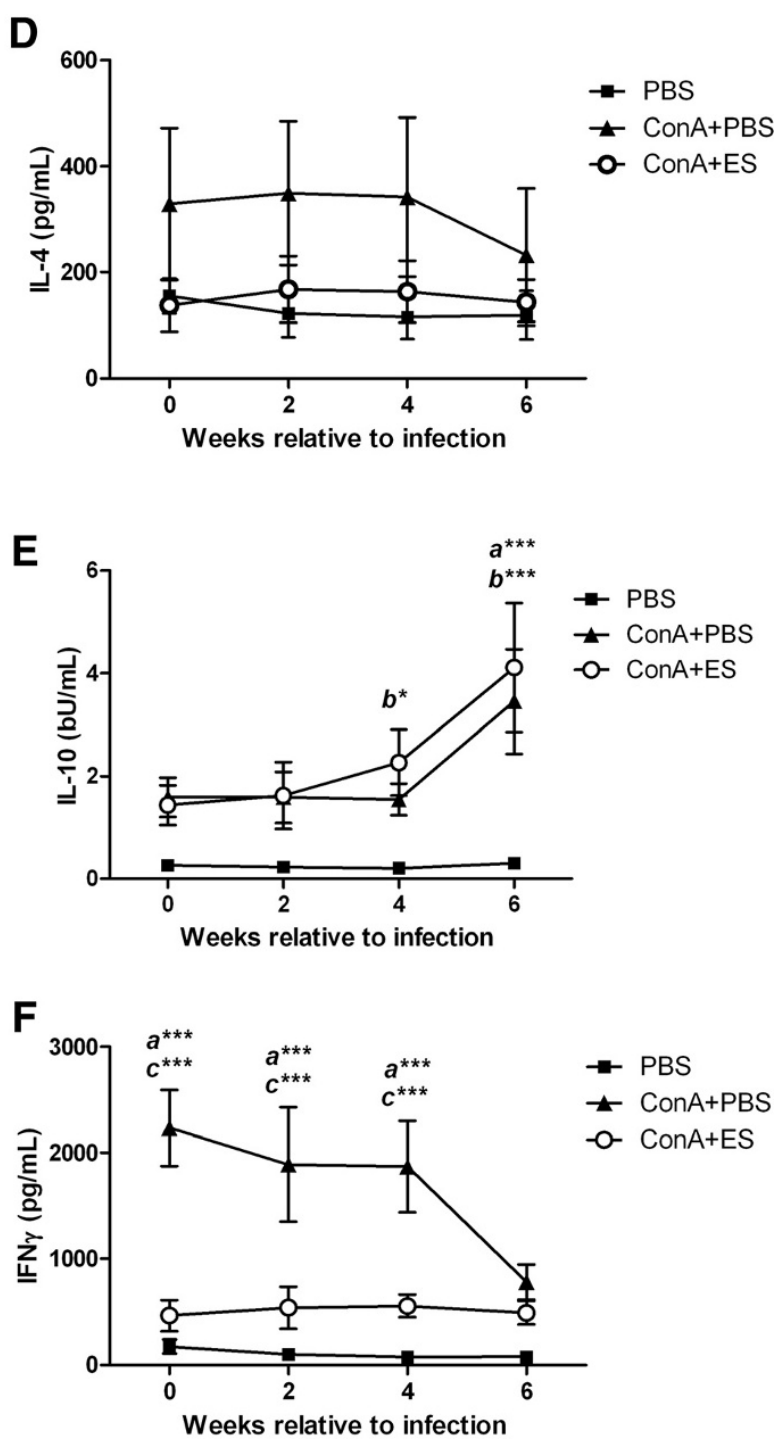

Figure 7 The effects of $T$. circumcincta infection on Tci-L4-ES mediated lymphocyte suppression. Seven helminth-naive lambs were trickle infected with $2000 \mathrm{~T}$. circumcincta L3 three times a week for four weeks. PBMC were harvested at 0, 2, 4 and 6 weeks from the start of infection and cultured for $72 \mathrm{~h}$ with PBS alone (PBS), $5 \mu \mathrm{g} / \mathrm{mL}$ Con A (Con A + PBS) or $5 \mu \mathrm{g} / \mathrm{mL}$ Con A + $15 \mu \mathrm{g} / \mathrm{mL}$ Tci-L4-ES (Con A + ES). Proliferation was assessed at $72 \mathrm{~h}$ by measurement of $\left.{ }^{3} \mathrm{H}\right]$ thymidine incorporation. Levels of cytokine present in the cell culture supernatants at $54 \mathrm{~h}$ were determined by ELISA. (A) Faecal egg count (FEC) data over the course of the experimental infection. (B) Proliferation of PBMC in response to PBS, Con A + PBS and Con A + ES during experimental T. circumcincta infection. (C) Levels of serum TCi-L4-ES-specific IgA and IgG during experimental T. circumcincta infection. (D-F) Concentrations of IL-4, IL-10 and IFN- $\gamma$ in PBMC cultures supernatants. Data represents mean \pm SEM. ${ }^{a}$ significant difference between Con A + PBS vs. PBS-stimulated cultures; ${ }^{b}$ significant difference between ConA + ES vs. PBS-stimulated cultures; ${ }^{c}$ significant difference between Con A + PBS vs. Con $A+$ ES stimulated cultures; ${ }^{*} P<0.05,{ }^{* *} P<0.01,{ }^{* * *} P<0.001$ (repeated-measures two-way ANOVA followed by the Bonferroni post hoc test for comparison of means).

The induction of Foxp $3^{+}$regulatory $\mathrm{T}$ cells has been shown to be an important mechanism by which certain parasites down-regulate the host immune response to enhance survival [41-45]. In this study, we confirmed that numbers of Foxp3 ${ }^{+} \mathrm{T}$ cells are elevated in the abomasa of animals in the early stages of infection when L4 stage parasites are predominant. However, within the abomasal mucosa, the proportions of $\mathrm{CD}^{+} \mathrm{T}$ cells expressing Foxp3 did not change before and after infection suggesting that, rather than being specifically induced by the parasite, the observed Foxp $3^{+} \mathrm{T}$ cell response to $T$. circumcincta infection during these early stages of infection may reflect a more homeostatic regulatory mechanism within the abomasal cellular immune response to minimize immune-mediated abomasal pathology. This would be consistent with subsequent observations that Tci-L4-ES did not induce an increase in the proportion of activated ovine lymphocytes expressing Foxp3 in vitro. 


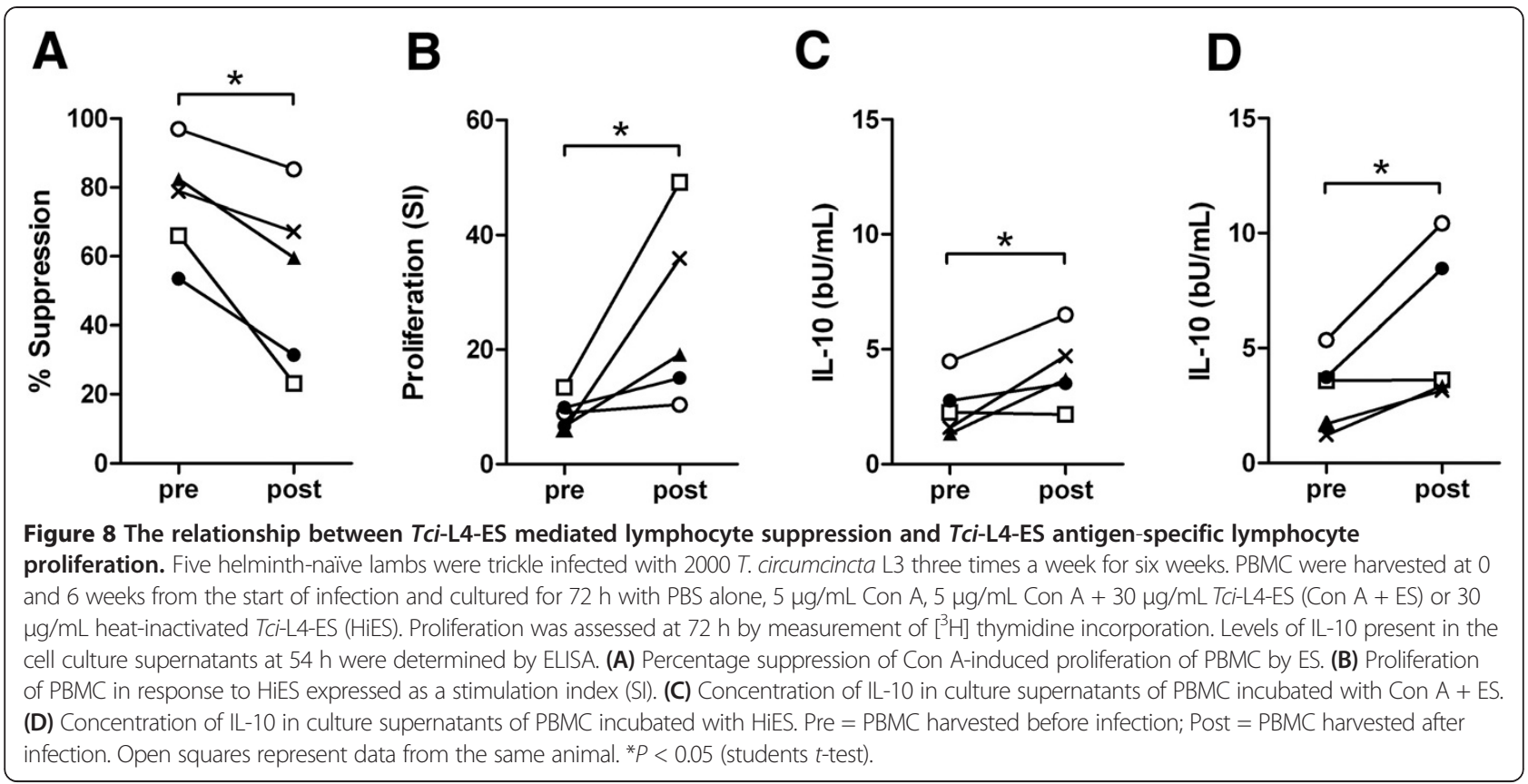

It should be noted that a relatively large single bolus infection (50 $000 \mathrm{~T}$. circumcincta L3) was used in this experiment which may not be truly reflective of parasite challenge in the field. Nevertheless, this infection protocol has been used widely in a number of previous studies (e.g. $[13,46,47])$ and is a useful model to explore the underlying mechanisms of immunity to $T$. circumcincta in helminthnaïve lambs as firstly, lower bolus infections of L3 have been shown to be poor at inducing abomasal immune responses in helminth-naive lambs [48] and secondly, low dose repeated trickle infections, which more accurately reflect challenge conditions in the field, are complicated by the presence of multiple parasitic stages within the abomasum, which makes interpretation of immune responses in relation to specific parasitic stages more complicated.

The lack of obvious Foxp3 induction in ovine lymphocytes by Tci-L4-ES is in contrast to results obtained in a previous study in which stimulation of murine $\mathrm{CD}^{+} \mathrm{T}$ cells with a combination of $\alpha-C D 3 / \alpha-C D 28$ antibody, IL-2 and an identical concentration of Tci-L4-ES, resulted in $\sim 20 \%$ increase in the proportion of cells expressing Foxp3 [15]. In the mouse study, induction of Foxp3 by Tci-L4-ES was attributed to TGF- $\beta$-like activity within the ES which is known to preferentially act on naïve $\mathrm{CD}^{+} \mathrm{T}$ cells to induce Foxp3 expression [15,33]. However, even culturing naïve $\mathrm{CD} 4^{+} \mathrm{T}$ cells $\left(\mathrm{CD} 4^{+} \mathrm{CD} 25^{-}\right.$ $\mathrm{CD}_{45 \mathrm{RA}^{+}}$) with $\mathrm{Tci}$-L4-ES failed to result in any increase in Foxp3 expression. The difference in the data between the mouse study and our own study may be due to a number of factors, including the use of purified $\mathrm{CD} 4^{+}$lymphocytes rather than PBMC cultures (as used here), different methods of polyclonal T cell stimulation $(\alpha-C D 3 / \alpha-C D 28$ antibody and IL-2 compared to Con A), or inherent differences between murine and ovine lymphocytes such as differential sensitivities to TGF- $\beta$ signaling or different requirements for induction of Foxp3 expression. However, the mouse study demonstrated that addition of Heligmosomoides polygyrus ES induced de novo Foxp3 expression in Con A-stimulated splenocyte cultures [15], a culture system similar to that employed here. Regardless of the cause of the differences in data between the two studies, the results here highlight the importance of utilizing cells derived from a parasite's definitive host to accurately define the appropriate host-parasite interactions.

Rather than inducing Foxp3 expression, the major effect that Tci-L4-ES had on ovine T lymphocytes was profound suppression of mitogen-stimulated and antigenspecific lymphocyte proliferation which was heat-labile in nature. This was associated with a lack of up-regulation of IL2-R $\alpha$ following mitogenic stimulation. As this receptor is expressed at an early stage in T cell activation [49], this indicates that Tci-L4-ES may interfere with early activation events. While the exact mechanism is still to be elucidated, suppression appeared to be associated with upregulation of IL-10 transcription and was partially blocked by specific monoclonal antibody neutralisation of IL-10. The latter is an anti-inflammatory and immunomodulatory cytokine produced my several immune cell types ( $\mathrm{T}$ cells, B cells and monocyte/macrophages) and is capable of suppressing $\mathrm{T}$ lymphocyte responses though a number of mechanisms. For example, IL-10 down-regulates expression of major histocompatibility complex class II 
proteins and co-stimulatory molecules, such as CD80 and CD86, on the surface of antigen presenting cells [50,51], thereby interfering with the generation and maintenance of $\mathrm{T}$ cell responses. IL-10 is also known to directly suppress $\mathrm{CD}^{+} \mathrm{T}$ cell proliferation by inhibiting IL-2 gene transcription [52]. The cellular source of IL-10 in our assays remains to be determined. We also observed a significant decrease in IL-4 transcription in Con A stimulated lymphocyte cultures when Tci-L4-ES was present. This may have biological relevance as protective immunity to T. circumcincta has been associated with Th2-type responses [13]. This effect was heat-stable indicating that different components within Tci-L4-ES are capable modulating IL-10 and IL-4 gene expression. Given the heat-stable nature of the ES-mediated down-regulation of IL-4, it is possible that contaminating LPS was responsible for the observation, as LPS is relatively heatstable and known to polarize towards a Th-1 type response [53].

While this is the first observation of lymphocyte suppression by an ovine parasitic nematode, a number of related pathogens exert similar effects in other species. Both ES products and somatic extracts from O. ostertagi L4 have been shown to suppress Con A-induced proliferation of bovine lymphocytes [17]. In this case, suppression was similarly associated with reduced expression of IL2-R $\alpha$ and up-regulation of IL-10 gene expression. $H$. polygyrus ES has been shown to suppress both antigen-specific antibody production and lymphocyte proliferation in vitro $[54,55]$ and Nippostryongylus brasiliensis adult ES was also demonstrated to suppress mitogen-induced proliferation [56]. With regard to ovine helminths, ES material derived from the ovine trematode, Fasciola hepatica, has been shown to be capable of suppressing mitogen-induced proliferation of both ovine and human lymphocytes [57]. One important question which relates to all in vitro experiments with parasite ES is how relevant the concentrations of ES used in vitro are to those encountered in vivo. While it is difficult to determine the exact concentration of Tci-L4-ES encountered by ovine lymphocytes in vivo, which may be influenced by both the proximity of lymphocytes to the parasite and the quantity of ES generated in vivo, the concentrations of ES used in this study were identical to those used in the murine study of Tci-L4-ES [15], and were not high enough to affect cell viability, neither inducing apoptosis or necrosis in the PBMC cultures.

One salient result here was the observed reduction in the suppressive capacity of Tci-L4-ES when the parasite extract was used in combination with PBMC derived from sheep which had been trickle infected with $T$. circumcincta to mimic challenge conditions in the field. The observed reduction in suppression was associated with an increase in circulating Tci-L4-ES-specific antibodies, an increase in Tci-L4-ES-antigen specific $\mathrm{T}$ cell proliferation, and occurred at a time in the infection protocol where we would have expected immuneinduced inhibition of L4 development [5]. The reduced "suppressive" effect of Tci-L4-ES on lymphocytes from infected sheep was thus likely associated with development of adaptive immunity. This indicates that despite obvious suppression of $\mathrm{T}$ cell activation by Tci-L4-ES in vitro, any potential suppressive effect that Tci-L4-ES exhibits in vivo was not sufficient to prevent the generation of Tci-L4-ES antigen specific $\mathrm{T}$ cell responses during $T$. circumcincta infection. Whether Tci-L4-ES has a modulating effect on the acquisition of immunity against $T$. circumcincta, for example by causing a delay in the development of parasite-specific adaptive immune responses, is as yet unclear.

During the first 4 weeks of experimental infection, cultures stimulated with Con A + ES released relatively more IL-10 and less IFN- $\gamma$, than cultures stimulated with Con A alone, consistent with the previous observation that Tci-L4-ES appears to induce increased relative gene expression of IL-10 in PBMC cultures. The lack of a significant increase in total IL-10 protein release from Con A + ES stimulated cultures compared to those stimulated with Con A alone may be explained by the observation that throughout the infection study, Con A + ES-stimulated cultures proliferated and therefore expanded to a lesser extent than those cultured with Con A without ES, and therefore produced relatively more IL-10 per cell than non-ES stimulated cultures. As Con A + ES stimulated cultures were observed to proliferate, there was an increase in IL-10, but not IFN- $\gamma$ production, suggesting that proliferating ES-antigen specific lymphocytes exhibited a Th-2 or regulatory phenotype. This was consistent with the observation that PBMC from infected lambs released more IL-10 following stimulation with heat-inactivated ES antigen compared to PBMC obtained prior to infection, indicating that proliferating ES-antigen specific lymphocytes secreted IL-10. That PBMC cultures at later time-points during infection which were less suppressed by Tci-L4-ES released more IL-10 seems somewhat contradictory to our previous findings that IL-10 signaling appeared to be an important mechanism of suppression. However, it may be that the timing of IL-10 signaling, rather than the total levels of IL-10, is critical for suppression. It also suggests that additional mechanisms other than IL-10 signaling are involved in the suppressive effects of Tci-L4-ES.

While proliferation levels of PBMCs to Con A remained constant throughout the $T$. circumcincta infection, by 6 wpi there appeared to be a switch in cytokine production from IFN- $\gamma$ to IL-10. This down-modulation of IFN- $\gamma$ production towards a more IL-10-dominated 
response has been demonstrated in other nematode infections [58,59] and may have profound implications for individuals co-infected with pathogens for which IFN- $\gamma$ /Th-1 type responses are associated with protective immunity. Such pathogens include a number of important endemic diseases of sheep including Chlamydophila abortus [60], Toxoplasma gondii [61] and Mycobacterium avium subspecies paratuberculosis [27] and it is possible that co-infection with $T$. circumcincta may have an effect on an individual's ability to cope with these pathogens. Therefore, in addition to the production losses associated with the parasite itself, $T$. circumcincta infections may have far wider consequences for sheep flock health.

In conclusion, this is the first study to identify immunosuppressive activity in ES products derived from an ovine parasitic nematode. While caution must be taken in extrapolating in vitro data to the more complex situation in vivo and the exact significance of Tci-L4-ES mediated immune suppression in vivo has yet to be determined, the immunosuppressive effects of Tci-L4-ES may represent a mechanism by which $T$. circumcincta interferes with the generation of protective immune responses in vivo, facilitating survival of the parasite within the host. Consequently, immunosuppressive molecules within Tci-L4-ES may be useful vaccine targets, a concept that is supported by the demonstration that immunization of cattle and sheep with the immunosuppressive protein cathepsin L from Fasciola hepatica induces significant levels of protection against this trematode [62]. Furthermore, the modulation of lymphocyte cytokine responses during $T$. circumcincta infection may have wider consequences on the susceptibility of individuals to other infectious agents and further emphasizes the need for adequate control of this parasitic nematode.

\section{Additional files}

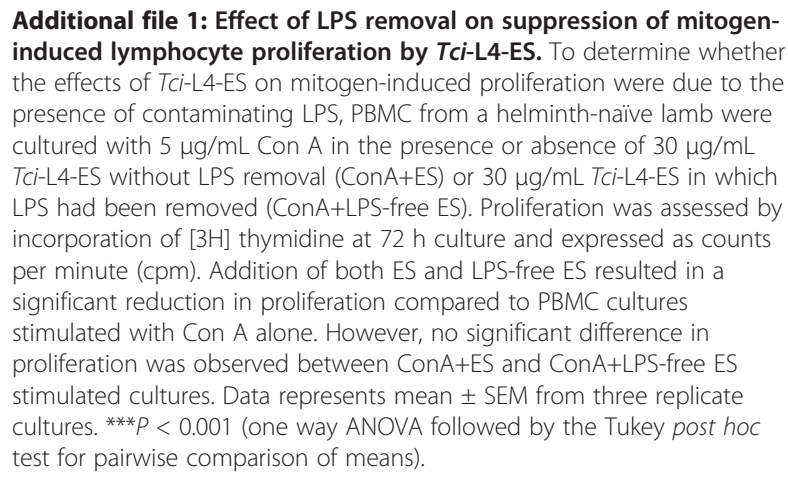
induced lymphocyte proliferation by Tci-L4-ES. To determine whether the effects of TCi-L4-ES on mitogen-induced proliferation were due to the presence of contaminating LPS, PBMC from a helminth-naïve lamb were cultured with $5 \mu \mathrm{g} / \mathrm{mL}$ Con A in the presence or absence of $30 \mu \mathrm{g} / \mathrm{mL}$ TCi-L4-ES without LPS removal (ConA+ES) or $30 \mu \mathrm{g} / \mathrm{mL}$ TCi-L4-ES in which LPS had been removed (ConA+LPS-free ES). Proliferation was assessed by incorporation of $[3 \mathrm{H}]$ thymidine at $72 \mathrm{~h}$ culture and expressed as counts per minute (cpm). Addition of both ES and LPS-free ES resulted in a significant reduction in proliferation compared to PBMC cultures stimulated with Con A alone. However, no significant difference in proliferation was observed between ConA+ES and ConA+LPS-free ES stimulated cultures. Data represents mean \pm SEM from three replicate cultures. ${ }^{* *} P<0.001$ (one way ANOVA followed by the Tukey post hoc test for pairwise comparison of means)

Additional file 2: Foxp3 expression in naïve $\mathrm{CD}^{+} \mathrm{T}$ cells following stimulation with Con A and Tci-L4-ES. $5 \times 10^{4}$ FACS sorted naïve CD4 ${ }^{+} \mathrm{CD}_{25} \mathrm{CD}^{-} 5 \mathrm{RA}^{+} \mathrm{T}$ cells from a helminth-naïve lamb were cultured with
$1 \times 10^{5}$ irradiated autologous antigen-presenting cells with PBS alone (PBS), $5 \mu \mathrm{g} / \mathrm{mL}$ Con A alone (ConA+PBS) or $5 \mu \mathrm{g} / \mathrm{mL}$ Con $A+30 \mu \mathrm{g} / \mathrm{mL}$ TCi-L4-ES (ConA+ES). After $72 \mathrm{~h}$ cells were labeled with anti-CD4-FITC and anti-Foxp3-PE-Cy7 antibodies and analysed by flow cytometry. Flow cytometry was performed in parallel on PBMC from the same lamb to validate the flow cytometry technique. (A) Representative plots of Foxp3 expression by $C D 4^{+} T$ cells following stimulation with ConA \pm TCi-L4-ES. (B) Percentages of $\mathrm{CD}^{+}$cells expressing Foxp3 from triplicate experiments. No significant difference in\% Foxp3 expression was seen (one way ANOVA). Data represents the mean \pm SEM. (C) Control flow cytometry labeling of PBMC for CD4 and Foxp3.

\section{Competing interests}

The authors declare that they have no competing interests.

\section{Authors' contributions}

TM designed the experiments, performed immunological and statistical analyses and drafted the manuscript. MR performed flow cytometry analyses. YB and LM carried out the parasitological analyses and assisted with animal experiments. DF carried out immunological analyses, ES preparation and assisted with animal experiments. JM and JKB performed immunohistochemical analyses. CL performed serological analyses. SW performed immunological analyses. AJN, JFH and JBM contributed to the design of the experiments and drafting of the manuscript. All authors read and approved the final manuscript.

\section{Acknowledgements}

This work was funded by Scottish Government core funding. SW is part funded by the "The route to identification of immunological correlates of protection in ruminants" Industrial Partnership Award funded by BBSRC (grant numbers BB/I019863/1; BB/I020519/1) with the support of AbD Serotec. The authors would like to thank Jeanie Finlayson and the Histopathology laboratory at Moredun Research Institute (MRI) for assistance with immunohistochemical labeling, Dr Judith McNeilly from the MRC Centre for Reproductive Health, The University of Edinburgh, Queen's Medical Research Institute, for assistance with confocal microscopy and $\mathrm{Mr}$ Robert Fleming from The Roslin Institute, University of Edinburgh, for assistance with FACS. The authors would also like to thank MRI Bioservices Division for the excellent care of experimental animals, to Dave Bartley and Alison Morrison from the MRI parasitology group for provision of $T$. circumcincta L3 and assistance with faecal egg counts.

\section{Author details}

'Moredun Research Institute, Pentlands Science Park, Bush Loan, Penicuik EH26 OPZ, UK. ' MRC Centre for Reproductive Health, Queen's Medical Research Institute, The University of Edinburgh, 47 Little France Crescent, Edinburgh EH16 4TJ, UK.

Received: 8 April 2013 Accepted: 29 July 2013

Published: 21 August 2013

\section{References}

1. McKellar QA: Interactions of Ostertagia species with their bovine and ovine hosts. Int J Parasitol 1993, 23:451-462.

2. Greer AW, Huntley JF, Mackellar A, McAnulty RW, Jay NP, Green RS, Stankiewicz M, Sykes AR: The effect of corticosteroid treatment on local immune responses, intake and performance in lambs infected with Teladorsagia circumcincta. Int J Parasitol 2008, 38:1717-1728.

3. Simpson HV: Pathophysiology of abomasal parasitism: is the host or parasite responsible? Vet J 2000, 160:177-191.

4. Kaplan RM, Vidyashankar AN: An inconvenient truth: global worming and anthelmintic resistance. Vet Parasitol 2012, 186:70-78.

5. Seaton DS, Jackson F, Smith WD, Angus KW: Development of immunity to incoming radiolabelled larvae in lambs continuously infected with Ostertagia circumcincta. Res Vet Sci 1989, 46:241-246.

6. Smith WD: Some observations on immunologically mediated inhibited Teladorsagia circumcincta and their subsequent resumption of development in sheep. Vet Parasitol 2007, 147:103-109.

7. Maizels RM, Balic A, Gomez-Escobar N, Nair M, Taylor MD, Allen JE: Helminth parasites-masters of regulation. Immunol Rev 2004, 201:89-116. 
8. Hewitson JP, Grainger JR, Maizels RM: Helminth immunoregulation: the role of parasite secreted proteins in modulating host immunity. Mol Biochem Parasitol 2009, 167:1-11.

9. McNeilly TN, Devaney E, Matthews JB: Teladorsagia circumcincta in the sheep abomasum: defining the role of dendritic cells in T cell regulation and protective immunity. Parasite Immunol 2009, 31:347-356.

10. Smith WD, Jackson F, Jackson E, Williams J: Age immunity to Ostertagia circumcincta: comparison of the local immune responses of $41 / 2-$ and 10-month-old lambs. J Comp Pathol 1985, 95:235-245.

11. Smith SK, Nisbet AJ, Meikle LI, Inglis NF, Sales J, Beynon RJ, Matthews JB: Proteomic analysis of excretory/secretory products released by Teladorsagia circumcincta larvae early post-infection. Parasite Immunol 2009, 31:10-19.

12. Smith WD, Jackson F, Jackson E, Graham R, Williams J, Willadsen SM, Fehilly CB: Transfer of immunity to Ostertagia circumcincta and IgA memory between identical sheep by lymphocytes collected from gastric lymph. Res Vet Sci 1986, 41:300-306.

13. Craig NM, Miller HR, Smith WD, Knight PA: Cytokine expression in naive and previously infected lambs after challenge with Teladorsagia circumcincta. Vet Immunol Immunopathol 2007, 120:47-54.

14. Maizels RM, Yazdanbakhsh M: Immune regulation by helminth parasites: cellular and molecular mechanisms. Nat Rev Immunol 2003, 3:733-744.

15. Grainger JR, Smith KA, Hewitson JP, McSorley HJ, Harcus Y, Filbey KJ, Finney CA, Greenwood EJ, Knox DP, Wilson MS, Belkaid Y, Rudensky AY, Maizels RM: Helminth secretions induce de novo T cell Foxp3 expression and regulatory function through the TGF-beta pathway. J Exp Med 2010, 207:2331-2341.

16. Klesius PH, Washburn SM, Ciordia H, Haynes TB, Snider TG 3rd: Lymphocyte reactivity to Ostertagia ostertagi $\mathrm{L} 3$ antigen in type I ostertagiasis. Am J Vet Res 1984, 45:230-233.

17. Gomez-Munoz MT, Canals-Caballero A, Almeria S, Pasquali P, Zarlenga DS, Gasbarre LC: Inhibition of bovine T lymphocyte responses by extracts of the stomach worm Ostertagia ostertagi. Vet Parasitol 2004, 120:199-214.

18. Jackson F, Christie MG: Further observations on faecal egg output in lambs dosed continuously with Ostertagia circumcincta. Res Vet Sci 1984, 36:375-377.

19. Burgess CGS, Bartley Y, Redman E, Nath M, Whitelaw F, Tait A, Gilleard JS, Jackson F: A survey of the trichostrongylid nematode species present on UK sheep farms and their associated anthelmintic control practices. Vet Parasitol 2012, 189:299-307.

20. Knox DP, Jones DG: Studies on the presence and release of proteolytic enzymes (proteinases) in gastro-intestinal nematodes of ruminants. Int J Parasitol 1990, 20:243-249.

21. McNeilly TN, Mclntyre J, Frew D, Griffiths DJ, Wattegedera SR, van den Broek A, Huntley JF: Infestation of sheep with Psoroptes ovis, the sheep scab mite, results in recruitment of Foxp3(+) T cells into the dermis. Parasite Immunol 2010, 32:361-369.

22. Rocchi MS, Wattegedera SR, Frew D, Entrican G, Huntley JF, McNeilly TN: Identification of CD4+CD25 high Foxp3+ T cells in ovine peripheral blood. Vet Immunol Immunopathol 2011, 144:172-177.

23. Mackay CR, Marston WL, Dudler L: Naive and memory T cells show distinct pathways of lymphocyte recirculation. J Exp Med 1990, 171:801-817.

24. Matthews K, Bailey SL, Gossner AG, Watkins C, Dalziel RG, Hopkins J: Gene gun-delivered pGM-CSF adjuvant induces enhanced emigration of two dendritic cell subsets from the skin. Scand J Immunol 2007, 65:221-229.

25. McNeilly TN, Baker A, Brown JK, Collie D, Maclachlan G, Rhind SM, Rhind SM, Harkiss GD: Role of alveolar macrophages in respiratory transmission of visna/maedi virus. J Virol 2008, 82:1526-1536.

26. Chaplin PJ, Casey G, De RR, Buchan G, Wood PR, Scheerlinck JP: The expression and biologic effects of ovine interleukin- 4 on $T$ and $B$ cell proliferation. J Interferon Cytokine Res 2000, 20:419-425

27. Smeed JA, Watkins CA, Rhind SM, Hopkins J: Differential cytokine gene expression profiles in the three pathological forms of sheep paratuberculosis. BMC Vet Res 2007, 3:18.

28. Pariset L, Cappuccio I, Ajmone-Marsan P, Bruford M, Dunner S, Cortes O, Erhardt G, Prinzenberg EM, Gutscher K, Joost S, Pinto-Juma G, Nijman IJ, Lenstra JA, Perez T, Valentini A, Econogene Consortium: Characterization of 37 breed-specific single-nucleotide polymorphisms in sheep. J Hered 2006, 97:531-534.

29. Kwong LS, Hope JC, Thom ML, Sopp P, Duggan S, Bembridge GP, Howard CJ: Development of an ELISA for bovine IL-10. Vet Immunol Immunopathol 2002, 85:213-223.
30. Hope JC, Kwong LS, Thom M, Sopp P, Mwangi W, Brown WC, Palmer GH, Wattegedera S, Entrican G, Howard CJ: Development of detection methods for ruminant interleukin (IL)-4. J Immunol Methods 2005, 301:114-123.

31. Wattegedera S, Sills K, Howard CJ, Hope JC, McInnes CJ, Entrican G: Variability in cytokine production and cell proliferation by mitogenactivated ovine peripheral blood mononuclear cells: modulation by interleukin (IL)-10 and IL-12. Vet Immunol Immunopathol 2004, 102:67-76.

32. Denham DA: The development of Ostertagia circumcincta in lambs. J Helminthol 1969, 43:299-310.

33. Tran DQ, Ramsey H, Shevach EM: Induction of FOXP3 expression in naive human CD4+FOXP3 T cells by T-cell receptor stimulation is transforming growth factor-beta dependent but does not confer a regulatory phenotype. Blood 2007, 110:2983-2990.

34. Buza JJ, Hikono H, Mori Y, Nagata R, Hirayama S, Aodon-geril, Bari AM, Shu Y, Tsuji NM, Momotani E: Neutralization of interleukin-10 significantly enhances gamma interferon expression in peripheral blood by stimulation with Johnin purified protein derivative and by infection with Mycobacterium avium subsp. paratuberculosis in experimentally infected cattle with paratuberculosis. Infect Immun 2004, 72:2425-2428.

35. Lybeck KR, Storset AK, Olsen I: Neutralization of interleukin-10 from CD14 (+) monocytes enhances gamma interferon production in peripheral blood mononuclear cells from Mycobacterium avium subsp. paratuberculosis-infected goats. Clin Vaccine Immunol 2009, 16:1003-1011.

36. Williams AR, Palmer DG: Interactions between gastrointestinal nematode parasites and diarrhoea in sheep: Pathogenesis and control. Vet J 2012, 192:279-285.

37. Outteridge PM: Development of cell-mediated immunity in young ruminants. J Dairy Sci 1985, 68:257-260

38. Gasbarre LC: Effects of gastrointestinal nematode infection on the ruminant immune system. Vet Parasitol 1997, 72:327-337.

39. Stear MJ, Bishop SC, Doligalska M, Duncan JL, Holmes PH, Irvine J, McCririe L, McKellar QA, Sinski E, Murray M: Regulation of egg production, worm burden, worm length and worm fecundity by host responses in sheep infected with Ostertagia circumcincta. Parasite Immunol 1995, 17:643-652

40. Strain SA, Bishop SC, Henderson NG, Kerr A, McKellar QA, Mitchell S, Stear MJ: The genetic control of IgA activity against Teladorsagia circumcincta and its association with parasite resistance in naturally infected sheep. Parasitology 2002, 124:545-552.

41. Belkaid Y, Piccirillo CA, Mendez S, Shevach EM, Sacks DL: CD4+CD25+ regulatory $T$ cells control Leishmania major persistence and immunity. Nature 2002, 420:502-507.

42. Blankenhaus B, Klemm U, Eschbach ML, Sparwasser T, Huehn J, Kuhl AA Loddenkemper C, Jacobs T, Breloer M: Strongyloides ratti infection induces expansion of Foxp3+ regulatory $T$ cells that interfere with immune response and parasite clearance in BALB/c mice. J Immuno/ 2011, 186:4295-4305

43. Gillan V, Devaney E: Regulatory T cells modulate Th2 responses induced by Brugia pahangi third-stage larvae. Infect Immun 2005, 73:4034-4042.

44. Taylor MD, Harris A, Babayan SA, Bain O, Culshaw A, Allen JE, Maizels RM: CTLA-4 and CD4+ CD25+ regulatory T cells inhibit protective immunity to filarial parasites in vivo. J Immunol 2007, 179:4626-4634.

45. Taylor MD, van der Werf N, Harris A, Graham AL, Bain O, Allen JE, Maizels RM: Early recruitment of natural CD4+ Foxp3+ Treg cells by infective larvae determines the outcome of filarial infection. Eur J Immunol 2009, 39:192-206.

46. Halliday AM, Routledge CM, Smith SK, Matthews JB, Smith WD: Parasite loss and inhibited development of Teladorsagia circumcincta in relation to the kinetics of the local IgA response in sheep. Parasite Immunol 2007, 29:425-434.

47. Simpson HV, Przemeck SM, Scott I, Pernthaner A: Effects of Teladorsagia (Ostertagia) circumcincta infection on lambs selected for high fleece weight. Vet Parasitol 2009, 165:256-264.

48. Smith WD, Jackson F, Jackson E, Williams J, Miller HR: Manifestations of resistance to ovine ostertagiasis associated with immunological responses in the gastric lymph. J Comp Pathol 1984, 94:591-601.

49. Waldmann TA: The structure, function, and expression of interleukin-2 receptors on normal and malignant lymphocytes. Science 1986, 232:727-732.

50. de Waal MR, Haanen J, Spits H, Roncarolo MG, te Velde A, Figdor C, Johnson K, Kastelein R, Yssel H, de Vries JE: Interleukin 10 (IL-10) and viral 
IL-10 strongly reduce antigen-specific human T cell proliferation by diminishing the antigen-presenting capacity of monocytes via downregulation of class II major histocompatibility complex expression. J Exp Med 1991, 174:915-924.

51. Ding L, Linsley PS, Huang LY, Germain RN, Shevach EM: IL-10 inhibits macrophage costimulatory activity by selectively inhibiting the upregulation of B7 expression. J Immunol 1993, 151:1224-1234

52. de Waal MR, Yssel H, de Vries JE: Direct effects of IL-10 on subsets of human CD4+ T cell clones and resting T cells. Specific inhibition of IL-2 production and proliferation. J Immunol 1993, 150:4754-4765.

53. McAleer JP, Vella AT: Educating CD4 T cells with vaccine adjuvants: lessons from lipopolysaccharide. Trends Immunol 2010, 31:429-435.

54. Rzepecka J, Lucius R, Doligalska M, Beck S, Rausch S, Hartmann S: Screening for immunomodulatory proteins of the intestinal parasitic nematode Heligmosomoides polygyrus. Parasite Immunol 2006, 28:463-472.

55. Telford G, Wheeler DJ, Appleby P, Bowen JG, Pritchard DI: Heligmosomoides polygyrus immunomodulatory factor (IMF), targets T-lymphocytes. Parasite Immunol 1998, 20:601-611.

56. Uchikawa R, Matsuda S, Arizono N: Suppression of gamma interferon transcription and production by nematode excretory-secretory antigen during polyclonal stimulation of rat lymph node T cells. Infect Immun 2000, 68:6233-6239.

57. Jefferies JR, Barrett J, Turner RJ: Immunomodulation of sheep and human lymphocytes by Fasciola hepatica excretory-secretory products. Int $\mathrm{J}$ Parasitol 1996, 26:1119-1121.

58. Eschbach ML, Klemm U, Kolbaum J, Blankenhaus B, Brattig N, Breloer M: Strongyloides ratti infection induces transient nematode-specific Th2 response and reciprocal suppression of IFN-gamma production in mice. Parasite Immunol 2010, 32:370-383.

59. Setiawan T, Metwali A, Blum AM, Ince MN, Urban JF Jr, Elliott DE, Weinstock $\mathrm{JV}$ : Heligmosomoides polygyrus promotes regulatory T-cell cytokine production in the murine normal distal intestine. Infect Immun 2007, 75:4655-4663.

60. Rocchi MS, Wattegedera S, Meridiani I, Entrican G: Protective adaptive immunity to Chlamydophila abortus infection and control of ovine enzootic abortion (OEA). Vet Microbiol 2009, 135:112-121.

61. Innes EA: Toxoplasmosis: comparative species susceptibility and host immune response. Comp Immunol Microbiol Infect Dis 1997, 20:131-138.

62. Mulcahy G, Dalton JP: Cathepsin L proteinases as vaccines against infection with Fasciola hepatica (liver fluke) in ruminants. Res Vet Sci 2001, 70:83-86.

doi:10.1186/1297-9716-44-70

Cite this article as: McNeilly et al:: Suppression of ovine lymphocyte activation by Teladorsagia circumcincta larval excretory-secretory products. Veterinary Research 2013 44:70.

\section{Submit your next manuscript to BioMed Central and take full advantage of:}

- Convenient online submission

- Thorough peer review

- No space constraints or color figure charges

- Immediate publication on acceptance

- Inclusion in PubMed, CAS, Scopus and Google Scholar

- Research which is freely available for redistribution 